\title{
Combustion of Low-Calorific Waste Biomass Syngas
}

\author{
Kamil Kwiatkowski • Marek Dudyński · Konrad Bajer
}

Received: 7 March 2012 / Accepted: 31 May 2013 / Published online: 19 June 2013

(C) The Author(s) 2013. This article is published with open access at Springerlink.com

\begin{abstract}
The industrial combustion chamber designed for burning low-calorific syngas from gasification of waste biomass is presented. For two different gases derived from gasification of waste wood chips and turkey feathers the non-premixed turbulent combustion in the chamber is simulated. It follows from our computations that for stable process the initial temperature of these fuels must be at least $800 \mathrm{~K}$, with comparable influx of air and fuel. The numerical simulations reveal existence of the characteristic frequency of the process which is later observed in high-speed camera recordings from the industrial gasification plant where the combustion chamber operates. The analysis of NO formation and emission shows a difference between wood-derived syngas combustion, where thermal path is prominent, and feathersderived fuel. In the latter case thermal, prompt and $\mathrm{N}_{2} \mathrm{O}$ paths of nitric oxides formation are marginal and the dominant source of NO is fuel-bound nitrogen.
\end{abstract}

Keywords Biomass $\cdot$ Waste $\cdot$ Gasification $\cdot$ Syngas $\cdot$ Turbulent combustion

K. Kwiatkowski $(\varangle) \cdot$ M. Dudyński · K. Bajer

Faculty of Physics, University of Warsaw, Pasteura 7, 02-093 Warsaw, Poland

e-mail:kamil@igf.fuw.edu.pl

K. Kwiatkowski · K. Bajer

Interdisciplinary Centre for Mathematical and Computational Modelling,

University of Warsaw, Pawińskiego 5a, 02-106 Warsaw, Poland

M. Dudyński

Modern Technologies and Filtration Sp. z o.o.,

Mokotowska 40/21, 00-543 Warsaw, Poland

M. Dudyński

Faculty of Mathematics, Informatics and Mechanics, University of Warsaw,

Banacha 2, 02-097 Warsaw, Poland 


\section{Introduction}

Refuse from the plants processing materials of biological origin is an important source of biomass. The waste of this kind is often very homogeneous, so that the technology of thermal processing can be developed. The quantity is relatively small and, in order to maximise profits avoiding costly transportation to the distant processing plants, it is advantageous to use small units employing reliable technology of up-draft gasifiers to produce energy for local consumption [1-4]. Examples of such solutions are installations gasifying feathers from poultry slaughterhouse [4], waste leather from tannery [5], low-quality fresh wood waste [5], spent mushroom substrate [6], RDF or municipal waste in small communities [5, 7].

In most installations the gas obtained through gasification is hot (sometimes $1,000 \mathrm{~K}$ ) and contains components which condense (liquid hydrocarbons) as well as solid particles. Such impurities make the gas unsuitable for direct use as fuel for the engines of the electric power generators. Methods of utilising this type of fuel for power generation are currently the field of active research [8]. However, when there is demand for heat and steady reception can be ensured, it is more economical to produce high-pressure steam. This is the option of choice for an installation fed with low-calorific biomass where nearly $50 \%$ of energy of the syngas leaving the gasifier is its heat content. In this case when gas is suitably purified and cooled for fuelling an engine its energy content becomes too low and the engine does not work properly.

Heat producing systems of this kind consist of a gasification chamber, combustion chamber and a boiler $[4,9]$. They are relatively cheap, reliable and easy to run and maintain. In such systems, especially those utilising material categorised as biological waste, strict environmental norms are imposed. One is the limit, set very low, on the amount of pollutants in the flue gases. Second is the minimum gas passage time, i.e., the requirement that gas in the combustion chamber must be subject to temperature in excess of $1,123 \mathrm{~K}$ for at least $2 \mathrm{~s}$. Also thermal efficiency of the system must exceed the mandatory threshold value. The minimum gas passage time requirement has implications for the design of the combustion chamber. Its volume must be sufficiently large and the locations of the oxidiser inlets must ensure, as much as possible, uniform passage time for all gas volume elements. A consequence of bad design would be, for example, large regions of slow recirculation and fast stream near the chamber axis. Generally bad design may lead to high $\mathrm{NO}_{x}$ emission.

Combustion process is often optimised on the basis of numerical modelling. For example, Wei et al. optimised inlet velocities in an industrial scale combustor to ensure low nitric oxide emission [10]. Other numerical works focusing on low $\mathrm{NO}_{x}$ emission from industrial or semi-industrial burners are described in [11-13]. It is reported that in a certain kind of industrial gas burner lower $\mathrm{NO}_{x}$ emission is due to fuel preconditioning inside the burner in that way that before combustion it is strongly diluted and preheated [14]. After this preconditioning the fuel is similar to low calorific syngas.

In Fig. 1 we show that standard burners $[15,16]$ for low grade fuels do not meet low $\mathrm{NO}_{x}$ emission requirements when waste biomass syngas is supplied. The levels of both $\mathrm{NO}_{x}$ and $\mathrm{CO}$ exceed the norms when such low-calorific gas produced in fixedbed gasification is burning [17].

Hence, combustion chambers for this type of syngas must be individually designed. In this work we show the results of numerical simulations, as well as measurements, 
Fig. 1 Emission of $\mathrm{NO}$ and $\mathrm{CO}$ from standard low-emission burner $[15,16]$ fuelled by low-calorific waste biomass syngas, adapted from [17]

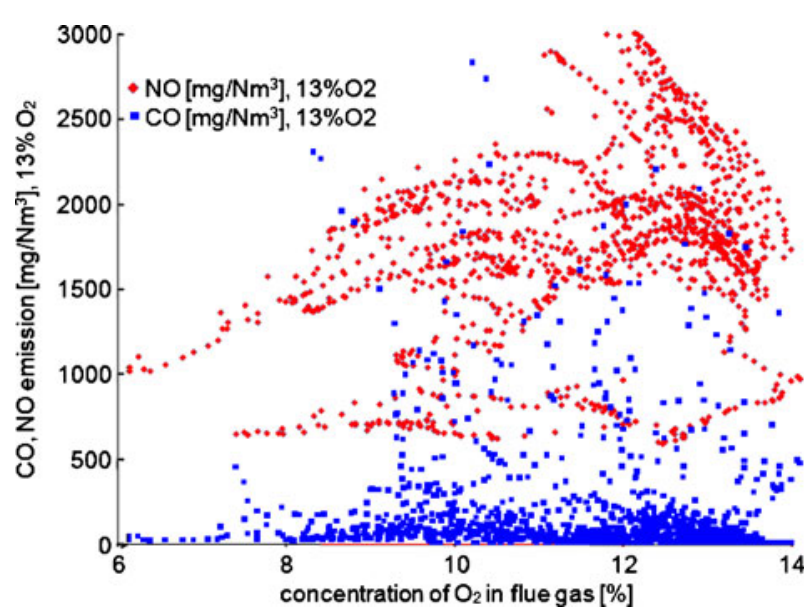

of combustion in two chambers custom-designed for burning low-calorific syngases. One chamber utilises syngas obtained from the gasification of poultry feathers (calorific value approximately $2 \mathrm{MJ} / \mathrm{Nm}^{3}$ ) and the other takes the syngas from waste wood chips (calorific value approximately $4.5 \mathrm{MJ} / \mathrm{Nm}^{3}$ ). We show that biomass syngas having very low calorific value, produced from low quality materials, can be burnt on industrial scale respecting environmental standards.

\section{Syngas from Biomass}

The processes occurring in an industrial gasifier include drying, pyrolysis and gasification $[8,18]$. The remaining char and gas undergo partial combustion providing energy necessary to maintain high temperature in the gasifier bed. The syngas leaving the gasifier is mixture of burnt and unburnt gaseous products of all these processes. The gas has low calorific value, but, for a given gasifier and type of biomass, relatively stable composition $[19,20]$.

In a fixed-bed system both quantity and quality of syngas do fluctuate. This is due to morphological changes in the bed, which cannot be easily controlled during the process. The bed may develop inhomogeneities, which change the pattern of air penetration and temperature distribution [4].

The fluctuations of the gas composition and temperature are also due to the varying characteristics of the biomass fed into the gasifier. The feed has variable calorific value, water content, composition, and mechanical properties. This affects the dynamics of the processes in the gasifier bed. Laboratory experiments [21] and data collected from the process control in industrial gasifiers [4] show that in order to achieve similar gasification dynamics the temperature of poultry feathers or tannery waste bed must be much higher (around 1,000 K) than that of wood [22].

Three main parameters of syngas leaving the gasifier, which instantaneously determine the conditions in the combustion chamber, are: temperature; flow rate and calorific value. Continuous, real time measurements of these parameters in a hot and 


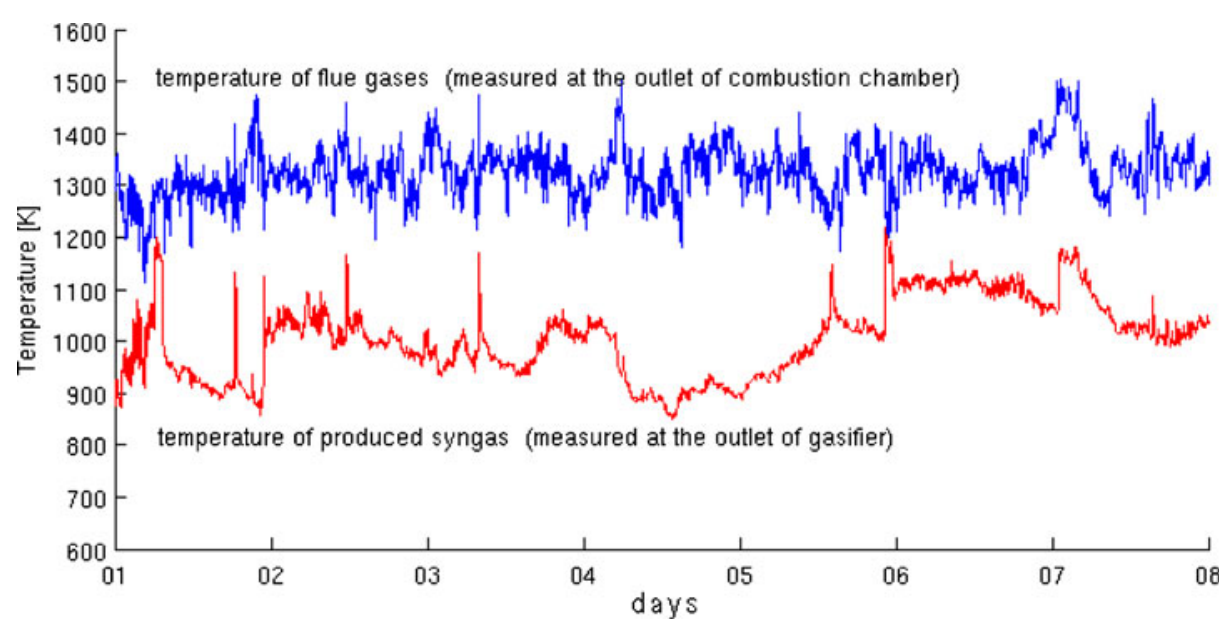

Fig. 2 Temperature of the syngas leaving the gasifier and temperature of the exhaust gases leaving the combustion chamber measured during one week (01-03-2011 to 07-03-2011) in the installation in Olsztyn. The averages are approximately 1,050 and 1,250 $\mathrm{K}$ respectively, with standard deviation of approximately $50 \mathrm{~K}$

chemically aggressive gas under the conditions of an industrial process are difficult. Often it is necessary to determine those parameters from indirect measurements, such as temperature and energy content of the exhaust gases leaving the combustion chamber $[19,20]$.

The installation in Olsztyn gasifies turkey and chicken feathers from a poultry slaughterhouse [4]. The average daily input is 1.5 tonne of biomass (water content appr. $50 \%$ ) yielding $3500 \mathrm{Nm}^{3}$ of syngas with chemical energy content of approximately $2 \mathrm{MJ} / \mathrm{Nm}^{3}$ (for cold gas). Similar apparatus for gasifying wood chips (appr. $30 \%$ water content) is installed in Szepietowo (Poland) [5, 22]. There the temperature is lower than in the gasifier in Olsztyn, but the temperature of syngas leaving the gasification chamber is just as stable (Fig. 2). High temperature and low

Table 1 Composition (dry-basis, tar-free, mass fractions) of biomass syngases produced in the fixedbed gasification from wood pellets [23], waste wood chips [5, 22] and turkey feathers [4]

\begin{tabular}{lllllll}
\hline Notation & $\begin{array}{l}\text { Wood } \\
\text { pellets }\end{array}$ & $\begin{array}{l}\text { Wood } \\
\text { pellets }\end{array}$ & $\begin{array}{l}\text { Wood } \\
\text { chips } \\
\text { SG1 }\end{array}$ & $\begin{array}{l}\text { Wood } \\
\text { chips } \\
\text { SG2 }\end{array}$ & $\begin{array}{l}\text { Turkey } \\
\text { feathers } \\
\text { SG3 }\end{array}$ & $\begin{array}{l}\text { Turkey } \\
\text { feathers } \\
\text { SG4 }\end{array}$ \\
\hline Nitrogen & 0.57 & 0.57 & 0.58 & 0.57 & 0.55 & 0.60 \\
Carbon monoxide & 0.32 & 0.28 & 0.28 & 0.36 & 0.03 & 0.07 \\
Hydrogen & 0.006 & 0.005 & 0.006 & 0.006 & 0.005 & 0.003 \\
Carbon dioxide & 0.08 & 0.13 & 0.12 & 0.09 & 0.40 & 0.30 \\
Oxygen & 0.003 & 0.003 & 0.000 & 0.000 & 0.000 & 0.014 \\
Methane & 0.012 & 0.010 & 0.012 & 0.010 & 0.020 & 0.015 \\
Ethane and propane & 0.005 & 0.002 & NA & NA & NA & NA \\
LHV [MJ/kg] & 4.81 & 4.13 & 4.2 & 4.50 & 1.91 & 1.80 \\
Stoichiometric mixture fraction & 0.455 & 0.488 & 0.478 & 0.465 & 0.630 & 0.662 \\
\hline
\end{tabular}

$N A$ not available 
calorific value of syngas makes direct burning the optimal solution. The installation in Olsztyn generates technological steam under pressure of $0.76 \mathrm{MPa}$.

Similar gasification plant is working in Szepietowo. In this plant an updraft fixedbed gasifier is fed by low-quality wood chips. The produced heat is directly used to dry saw dust for the production of pellets.

The parameter of syngases produced in Olsztyn and Szepietowo are given in Table 1. The gases were cleaned in scrubbers before its composition was measured in a chromatograph [23]. Hence, the compositions in Table 1 are those of clean, dry gas free of tars and liquid hydrocarbons. The LHV shows fluctuations typical for gasification of biomass. The stability of the whole process is confirmed by the longterm analysis $[19,20]$.

\section{Numerical Modelling}

\subsection{Flame structures}

In a non-premixed turbulent flow the flame occurs within thin sheet, called flamelet, close to the isosurface of stoichiometric composition [24]. According to the flamelet analysis the flame can be formally transformed from the physical space into onedimensional space of mixture fraction [25]. In the mixture fraction space the most important processes are species diffusion and reactions, so the simplified flamelet equations take the form [26]:

$$
\begin{array}{r}
\frac{1}{2} \rho \chi \frac{\partial^{2} Y_{\alpha}}{\partial \xi^{2}}+\omega_{\alpha}=0 \\
\frac{1}{2} \rho \chi \frac{\partial^{2} T}{\partial \xi^{2}}-\frac{1}{c_{p}} \sum H_{\alpha} \omega_{\alpha}+\frac{\rho \chi}{2 c_{p}}\left(\frac{\partial c_{p}}{\partial \xi}+\sum c_{p_{\alpha}} \frac{\partial Y_{\alpha}}{\partial \xi}\right) \frac{\partial T}{\partial \xi}=0
\end{array}
$$

The notation is as follows: $Y_{\alpha}$-mass fraction of specie $\alpha, \xi$-variable in mixture fraction space, $\chi$-scalar dissipation rate, $\omega_{\alpha}$-reactions rate for specie $\alpha, H_{\alpha}$-heat of reactions for specie $\alpha, \rho$-density of gas mixture, $c_{p}$-specific heat of gas mixture.

The oxidiser is air with temperature of $300 \mathrm{~K}$ for all cases. The fuels are syngases derived from wood (samples SG1-SG2) and from feathers (samples SG3-SG4), their mass fractions $Y_{\alpha}$ are presented in Table 1. We consider three levels of fuel preheating: $800,1,000$ and 1,200 $\mathrm{K}$ and cold fuel $(300 \mathrm{~K})$. The assumed levels of fuel preheating cover the whole range of possible fluctuation of syngas temperature (shown in Fig. 2).

The set of Eqs. 1 and 2 was solved with ANSYS Fluent code on 150 points grid. The solutions were in agreement with the results from additional tests with 200 and 500 points grid. The main combustible species in the biomass syngases are hydrogen, carbon monoxide and methane, which makes GRI3 [27] the mechanism of choice. The mechanism is based on 5 elements and 53 species appropriate for the particular syngases we consider. The total number of 325 reactions makes it manageable in terms of computational effort. We compare the results from GRI3 with the results from two other combustion mechanisms ('San Diego' mechanism [28] and 'Westbrook' mechanism [29]). The agreement is good. The detail calculations are presented in Appendix. Since GRI3 was recently used for modelling of diluted low calorific preheated fuel combustion $[30,31]$ we continue with this mechanism. 
For low-calorific syngases burning with air, the stoichiometry ratio is close to unity so the amount of syngas is comparable with the amount of oxidiser. Such a case is quite different from the situation typically encountered, and most often investigated, where the stoichiometric mixture contains much more oxidiser than fuel. For example, burning one cubic metre of methane requires more than $10 \mathrm{~m}^{3}$ of air. The implication of this unusually high stoichiometric ratio is that the enthalpy surplus, known to influence combustion, can equally well be delivered to the combustion chamber in hot fuel, as through preheating of air, as is the case in the of MILD regime (e.g. $[13,32])$.

Figure 3 shows, not surprisingly, that maximum temperature of combustion increases with increasing temperature of fuel inlet stream. However, the difference between those two temperatures, i.e., the 'boost' in temperature caused by the combustion process decreases, so the regime gets closer to MILD combustion. This result is in agreement with those discussed in [30, 31]. The difference between peak and inlet fuel temperature is smaller for the low-calorific syngas derived from feathers.

Another conclusion from the computations is that the peaks of the $\mathrm{OH}$ profiles in the mixture fraction space (Fig. 4) are lower for gases derived from feathers than for gases from wood chips.

The solutions of Eqs. 1 and 2 depend not only on reactants temperature and composition but also on scalar dissipation rate $\chi$. The dependence on $\chi$ manifests itself as the maximum temperature of the combustion process decreases with increasing scalar dissipation rate eventually leading to flame extinction. In Fig. 5 this dependence is plotted for all investigated syngases.

One can notice that the syngas derived from feathers (samples SG3 and SG4) is not flammable until preheated to at least $800 \mathrm{~K}$. Even then scalar dissipation rate has to be lower than $50 \mathrm{~s}^{-1}$. When initial temperature of fuel exceeds $1,000 \mathrm{~K}$

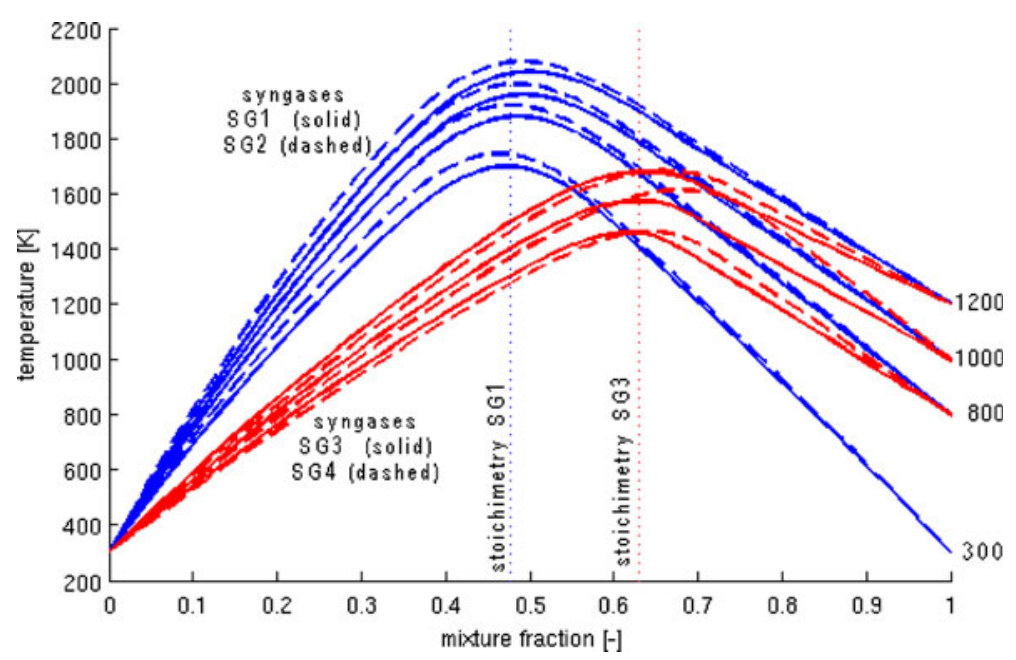

Fig. 3 The temperature of the syngases in mixture fraction space for scalar dissipation rate equal $5 \mathrm{~s}^{-1}$. Blue lines: SG1 (solid) and SG2 (dashed). Red lines SG3 (solid) and SG4 (dashed). Initial temperatures: $300,800,1,000$ and $1,200 \mathrm{~K}$ 
Fig. 4 Profiles of $\mathrm{OH}$ for scalar dissipation rate equal $5 \mathrm{~s}^{-1}$. Blue lines: SG1 (solid) and SG2 (dashed). Red lines SG3 (solid) and SG4 (dashed), see Table 1). Initial temperatures: 300, 800, 1,000 and $1,200 \mathrm{~K}$

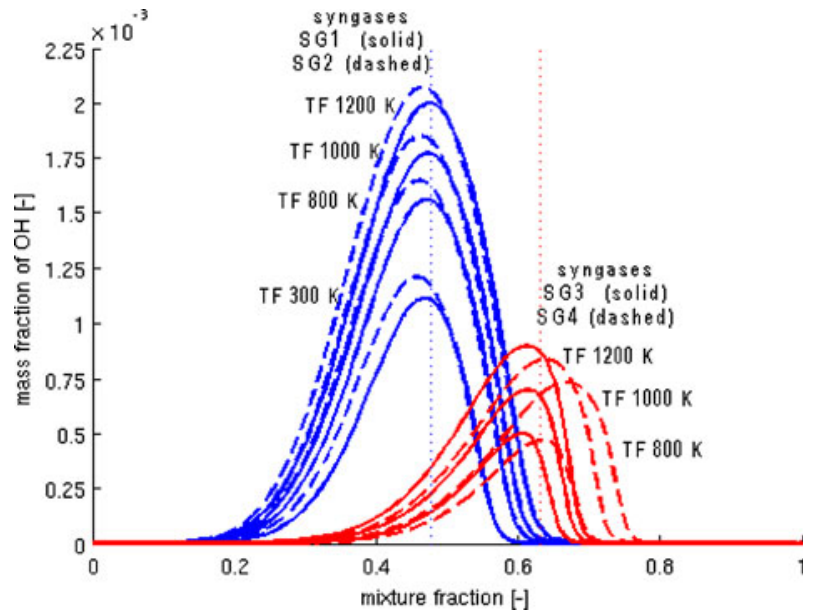

the reactions are sustained in a wider range of scalar dissipation rates: $200 \mathrm{~s}^{-1}$ or higher. Cold syngas derived from wood (samples SG1 and SG2) is flammable if scalar dissipation rate is smaller than $300 \mathrm{~s}^{-1}$ otherwise it must be preheated to at least $800 \mathrm{~K}$. When the initial temperature of syngas is higher than $1,000 \mathrm{~K}$ combustion of syngases produced from wood chips is stable even for high scalar dissipation rate.
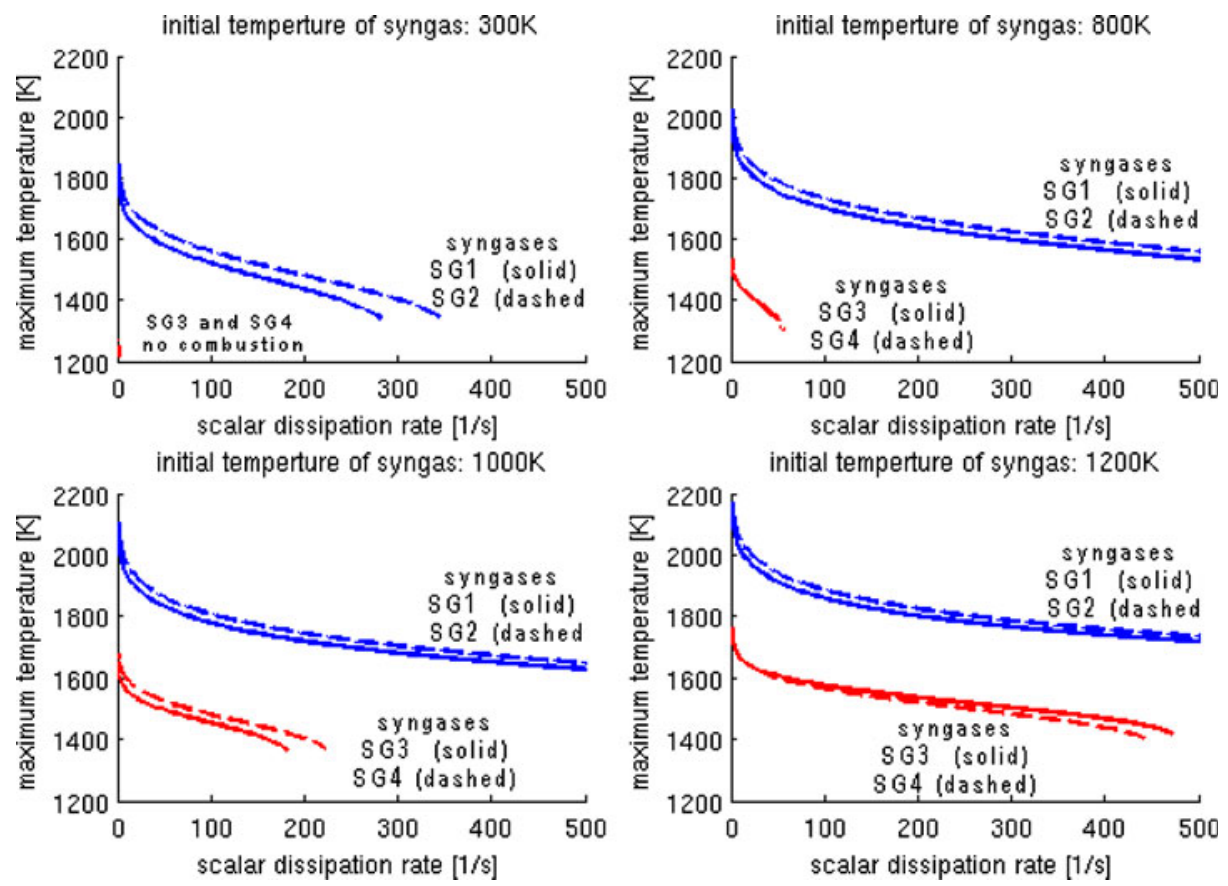

Fig. 5 Maximum temperature of the flame as a function of the scalar dissipation rate for different initial syngases temperature (SG1, SG2, SG3 and SG4, see Table 1) 
These results are in agreement with the results from the industrial installation in Olsztyn and Szepietowo. The process of combustion becomes stable and selfsustainable only when syngas produced from feathers is hot and the combustion chamber is heated to at least $800 \mathrm{~K}$. If these conditions are not met, auxiliary oil burner is necessary to sustain combustion.

As we see in Figs. 3-5 samples of gases derived from the same biomass (SG1SG2 and SG3-SG4) have similar properties. We decided to analyse further only one sample produced from wood (SG1) and one produced from feathers (SG3).

\subsection{CFD modelling}

The three-dimensional Unsteady RANS simulations are performed using the commercial CFD code ANSYS Fluent 13.0. Turbulence is modelled with standard $k-\epsilon$ closure. During simulations we simultaneously compute: turbulent flow, energy transfer, radiation and non-premixed combustion. In the post-processing stage the pollutants emission is calculated and will be discussed separately in Section 4.3.

The optical thickness of the flame is not well determined and optimal radiation model should be applicable in a wide range of optical thickness values. It makes the Discrete Ordinates Methods the approach of choice. The radiation properties of gases are defined according to the weighted sum of gray gases (WSGG). The WSGG seems to be a reasonable computational compromise between oversimplified gray gas model and the detailed model, considering absorption bands of gases.

Chemical reactions are introduced by the steady flamelet library discussed in Section 3.1. The GRI3 kinetic mechanism is used.

Our method $(k-\epsilon$ turbulence closure, DO Methods for radiation, Steady Flamelets and GRI3 for combustion) is well known and verified. This set of computational methods is often applied tolab-scale and pilot-scale combustion chambers, but is seldom used for simulations of industrial combustors.

We used transient pressure-based solver. Second-order upwind scheme was applied for space derivatives of advection terms in all transport equations. The PISO algorithm is used for velocity and pressure coupling.

The computational grid, described in detail in the next Section (Section 3.3), consists of $4.5 \times 10^{6}$ cells. The parallel computations were performed using 16 processors.

\subsection{Geometry and boundaries}

The geometrical model of the combustion chamber is based on the shape and dimensions of the unit working in the gasification plant in Olsztyn (Fig. 6). The size of this combustion chamber is $5.5 \mathrm{~m}$ height and $1.3 \mathrm{~m}$ radius, which makes approximately $30 \mathrm{~m}^{3}$ of volume. Fully three-dimensional computational mesh presented in Fig. 6 consists of about 4.5 millions hexa-type cells.

Both the syngas and the oxidizer (air) are supplied separately, so the combustor works in the non-premixed mode. The model includes of one central fuel inlet, two side air inlets, additional six small inlets at the top and one big outlet in the side wall near the bottom. The location of air distribution inlets to the combustion chamber is constrained by the environmental regulations. The time of residence of burning waste gases must be determined based on the location of the last air supply point. 


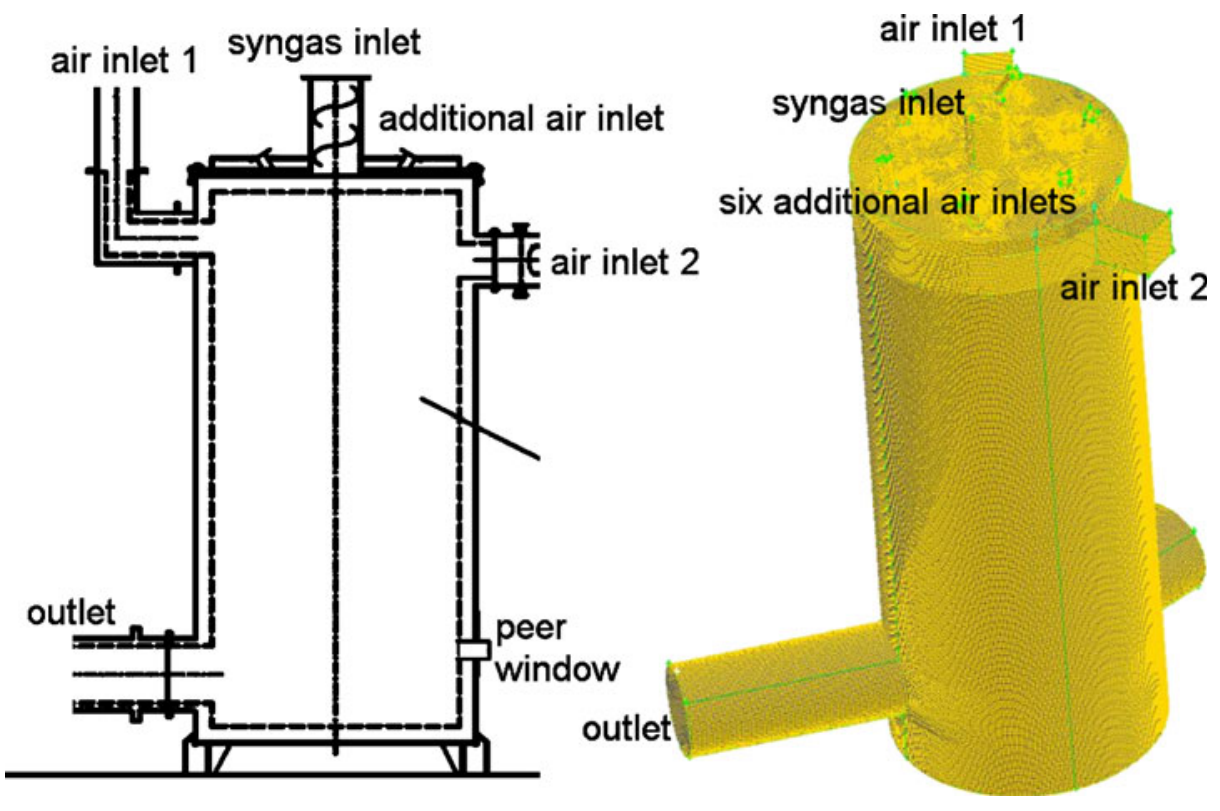

Fig. 6 Combustion chamber (left) and computational mesh (right). The syngas is supplied from the top. Air enters through two lateral inlets. Additionally small amount of air inflows through six inlets located on the top of the chamber

This is the reason why air distribution inlet pipes should be localised close to the fuel inlet. Typical combustors for burning low-calorific fuels are equipped with several air inlets distributed along combustion chambers. In case of burning waste syngases such approach leads to very large combustion chambers and is avoided for economic reasons.

The air is supplied through two lateral air inlets. The first inlet provides $1.2 \mathrm{~kg} / \mathrm{s}$ (air inflow velocity $6.25 \mathrm{~m} / \mathrm{s}$ ) and the second inlet $-0.3 \mathrm{~kg} / \mathrm{s}$ with air velocity equal $1.55 \mathrm{~m} / \mathrm{s}$. The inflowing air temperature is assumed to be $300 \mathrm{~K}$. Additionally $0.5 \mathrm{~kg} / \mathrm{s}$ of air is distributed via six small auxiliary inlets located at the top of the burner.

The hot syngas is supplied by the fuel inlet located in the top of the chamber. The temperature of the inflowing syngas is $1,000 \mathrm{~K}$ (which is the average measured temperature, see Fig. 2). Two cases with different rates of syngas production are considered. The first, when the syngas production is relatively high and equals approximately $1.4 \mathrm{~kg} / \mathrm{s}$, which at high temperature of gas $(1,000 \mathrm{~K})$ corresponds to $40 \mathrm{~m} / \mathrm{s}$ inlet velocity. In the second case we assume relatively low syngas production equal of $0.5 \mathrm{~kg} / \mathrm{s}$, which gives $15 \mathrm{~m} / \mathrm{s}$ fuel inlet velocity. The analysed cases are summarised in Table 2.

Table 2 List of four considered cases

\begin{tabular}{lll}
\hline Flow rate & Fuel & Simulations \\
\hline Low syngas production & SG1 (wood chips) & case 1A \\
$(0.5[\mathrm{~kg} / \mathrm{s}])$ & SG3 (feathers) & case 1B \\
High syngas production & SG1 (wood chips) & case 2A \\
$(1.40[\mathrm{~kg} / \mathrm{s}])$ & SG3 (feathers) & case 2B \\
\hline
\end{tabular}


In an industrial combustion chamber the walls are insulated to minimise the heat loses. The energy balance determined for period of one year based on process data from Olsztyn [20] reveals that insulation is efficient and heat loses through the walls do not exceed $3 \%$. Thus, in numerical modelling, we make a plausible assumption of zero heat flux through the walls.

\section{Results and Discussion}

\subsection{Time-dependence}

Direct observations of the combustion chamber in an industrial plant provide evidence that the flow seems to have a characteristic frequency. Standard-speed and high-speed camera recordings have been made through an observation window located in the bottom part of the combustion chamber, opposite the outlet pipe, as marked in Fig. 6. The recordings show that the dominant mode of combustion is oscillatory with the characteristic time of the order of seconds. Two main modes can be observed: (1) gases are homogeneously hot but no flames are visible; (2) entire bottom part of the chamber is filled with visible flames. The first mode is the dominant, the latter takes less than one second per oscillation.

The representative 30 seconds-long recording from high-speed camera (400 frames per second) is shown in Fig. 7. During 30 seconds one can see that the bottom part of the combustion chamber is lighted six times. Every lightening, shown in Fig. 7 with black frames, takes approximately $0.75 \mathrm{~s}$. The characteristic time of these oscillations is 5-6 seconds.

High-speed camera recordings, with time resolutions varying from 400 frames per second to 10,000 frames per second, reveal two other modes with time scales of the order of $0.1 \mathrm{~s}$. These faster modes are the following: (3) clockwise flame vortices appearing momentarily and then being transported by the flow to the outlet; (4) anticlockwise flame vortices which are flowing to the outlet. In Fig. 7 these fast modes can be seen (marked with dashed frames) approximately one second after the flame fills the lower part of the combustion chamber.

Numerical simulations reproduce those observations for both types of syngas, SG1 and SG3. Figure 8 shows how the stoichiometric iso-surface of mixture fraction (for SG1 equal 0.48) oscillates during combustion. The oscillation starts with the jet reaching only a third of the height of the combustion chamber (Fig. 8a) and increases its length while moving towards the wall (Fig. 8b-d). After that the jet shrinks (Fig. 8e-g). This takes about 6 seconds and then repeats (Fig. 8h-1). We follow this behaviour and find it steadily sustained in a one-minute simulation. The oscillatory mode has been observed also in the preliminary results from modelling based on Large Eddy Simulations [33].

\subsection{Temperature distribution}

The distribution of temperature, as described in the previous section, is time dependent. The oscillatory character of the process is observed for all analysed cases. 


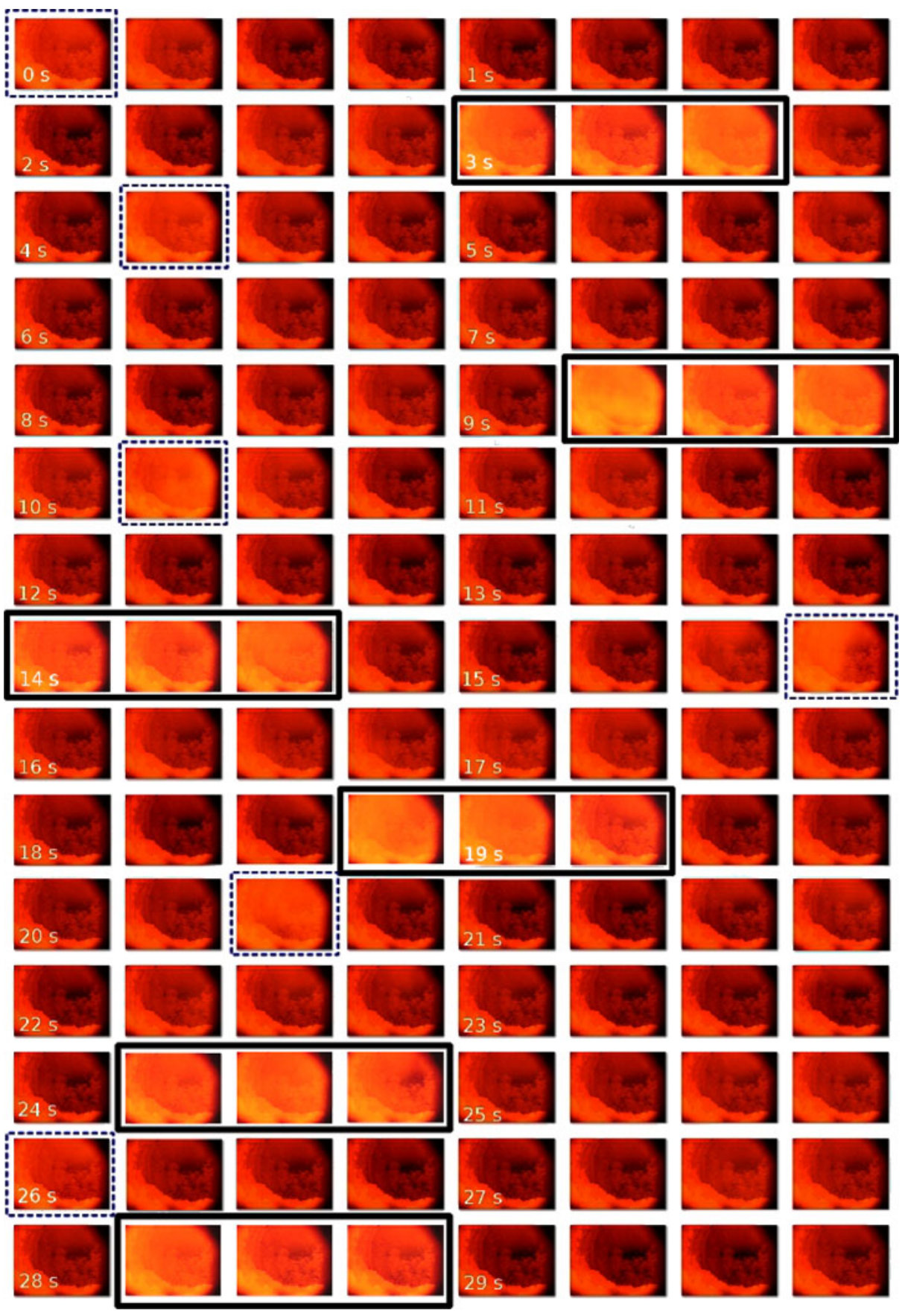

Fig. 7 The high-speed recording (400 frames per second) via the peer window located in bottom part of combustion chamber (see Fig. 6). The oscillations are marked with black frame 


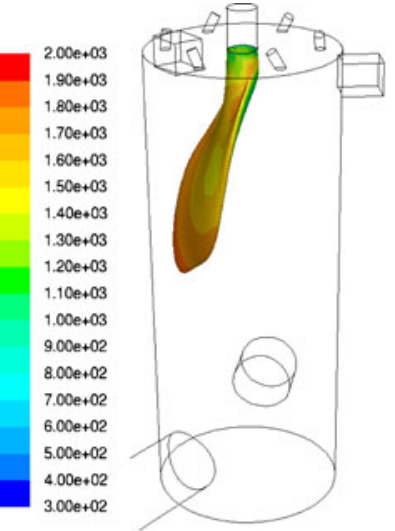

(a) $\mathrm{t}=0 \mathrm{~s}$

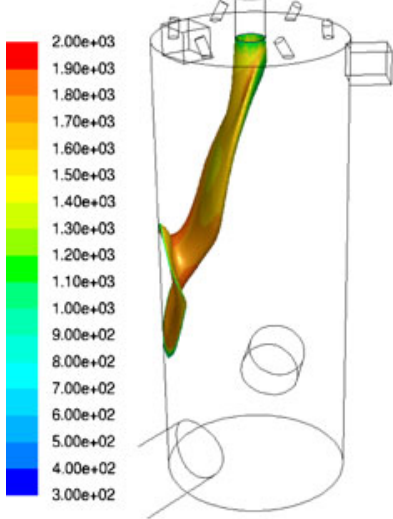

(e) $t=4 s$

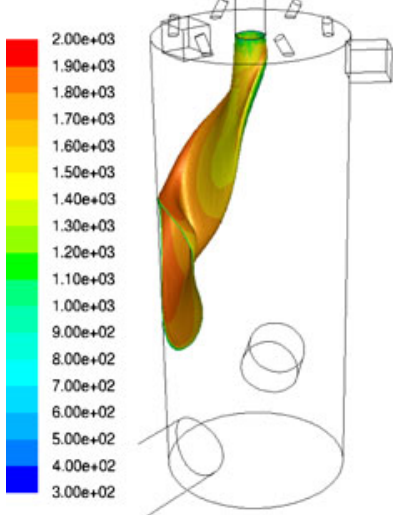

(i) $\mathrm{t}=8 \mathrm{~s}$

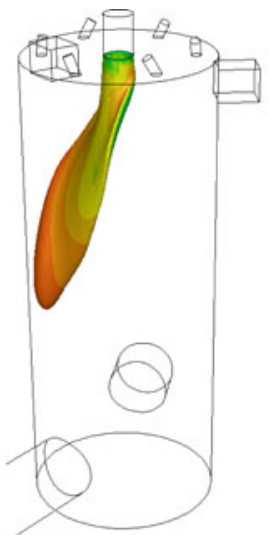

(b) $\mathrm{t}=1 \mathrm{~s}$

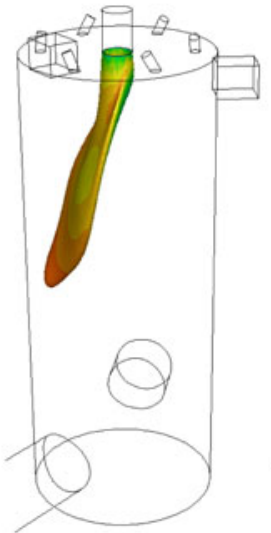

(f) $t=5 \mathrm{~s}$

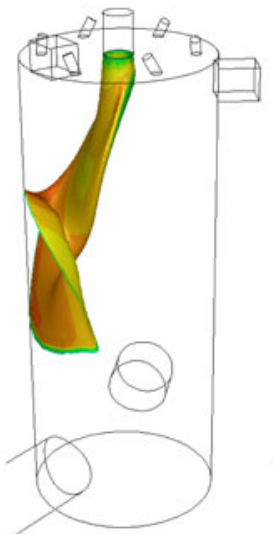

(j) $t=9 s$

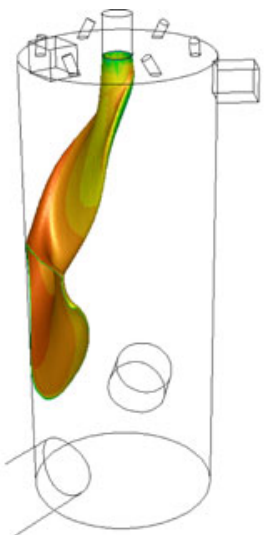

(c) $\mathrm{t}=2 \mathrm{~s}$

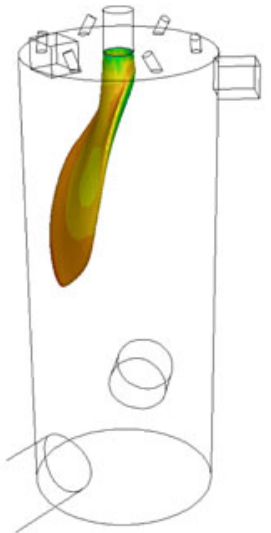

(g) $\mathrm{t}=6 \mathrm{~s}$

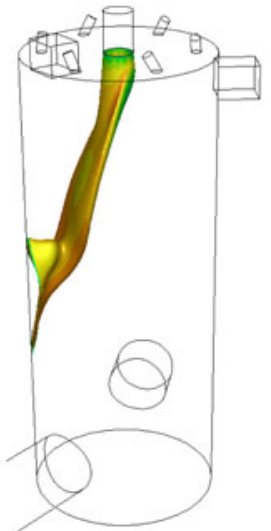

(k) $\mathrm{t}=10 \mathrm{~s}$

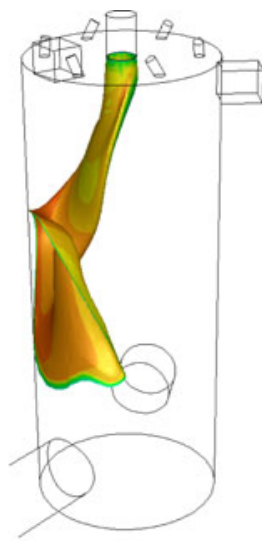

(d) $\mathrm{t}=3 \mathrm{~s}$

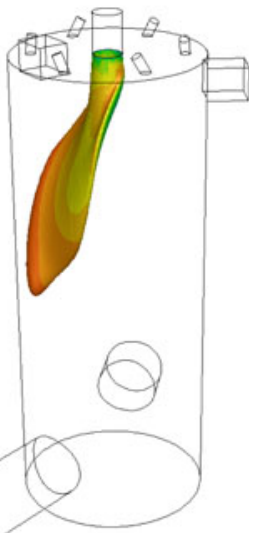

(h) $\mathrm{t}=7 \mathrm{~s}$

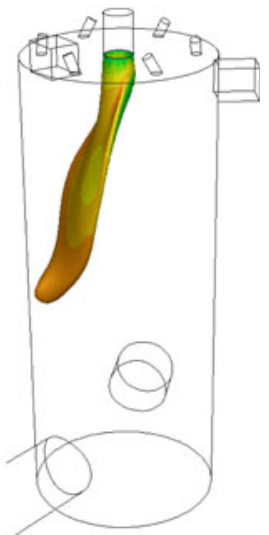

(1) $\mathrm{t}=11 \mathrm{~s}$

Fig. 8 Iso-surface of the mixture fraction equal 0.48 (stoichiometric value for syngas SG1) coloured by temperature 
Figures 9 and 10 show the temperature field within the combustion chamber for the first three seconds of the cycle (first half of the oscillation). To stress the differences in maximum temperature between cases when low calorific gas from wood (SG1: cases 1A and 2A) and lower calorific gas from feathers are burnt (SG3: cases $1 \mathrm{~B}$ and $2 \mathrm{~B}$ ) we used different scales for the figures. Figure 9 showing the results for SG1 is scaled to 2,000 K, while Fig. 10 showing the results for SG3 is scaled only to $1,500 \mathrm{~K}$.

The main feature of the process is that the location of the hottest part of the jet, seen in Fig. 8, is roughly at half-height of the combustion chamber. The ambient air is supplied from the top of the chamber and consequently this part is colder. The

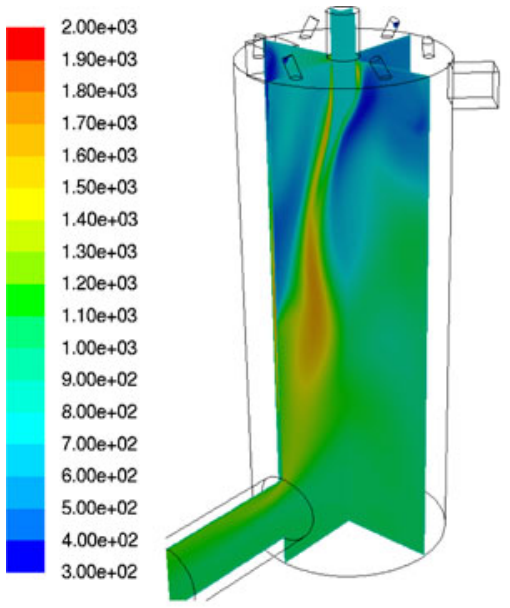

(a) $\mathrm{t}=0 \mathrm{~s}$

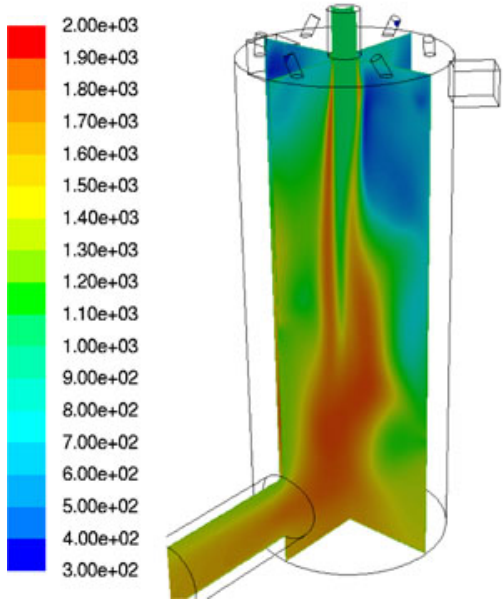

(d) $\mathrm{t}=0 \mathrm{~s}$

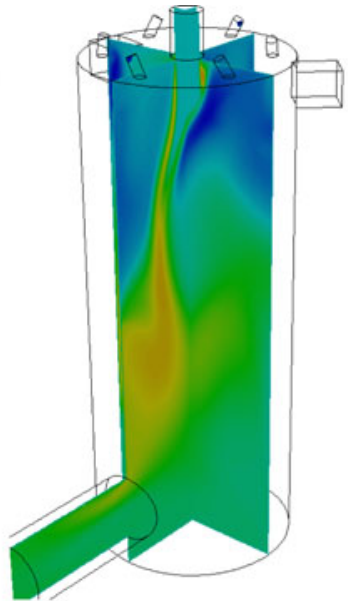

(b) $\mathrm{t}=1 \mathrm{~s}$

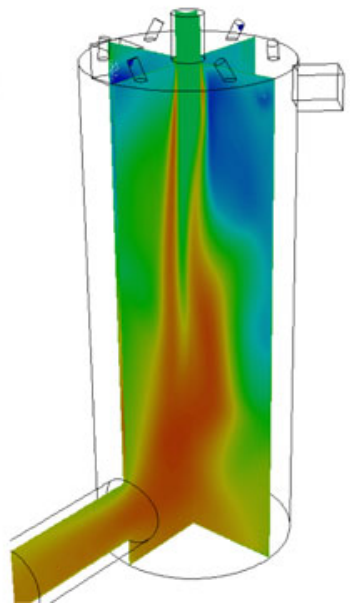

(e) $t=1 s$

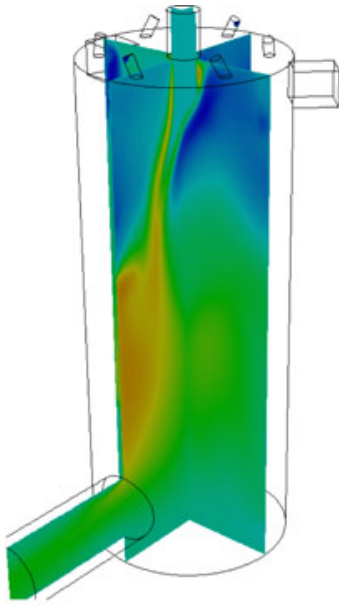

(c) $t=2 s$

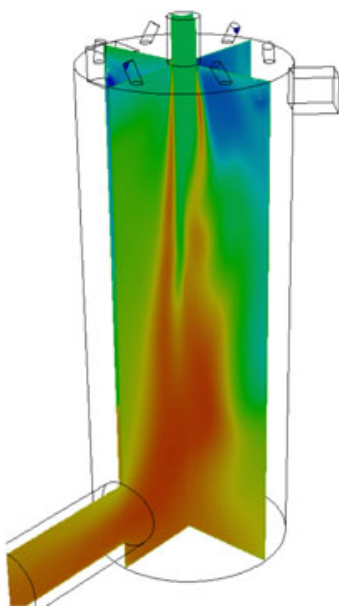

(f) $t=2 s$

Fig. 9 Temperature field in the combustion chamber. The syngas derived from wood (SG1) is burning with small and large syngas flux (gasifier output): $\mathbf{a}, \mathbf{b}$ and $\mathbf{c}-$ low syngas production-case 1A (scale 300-2,000 K); d, e and $\mathbf{f}$ - high syngas production—case 2A (scale 300-2,000 K) 


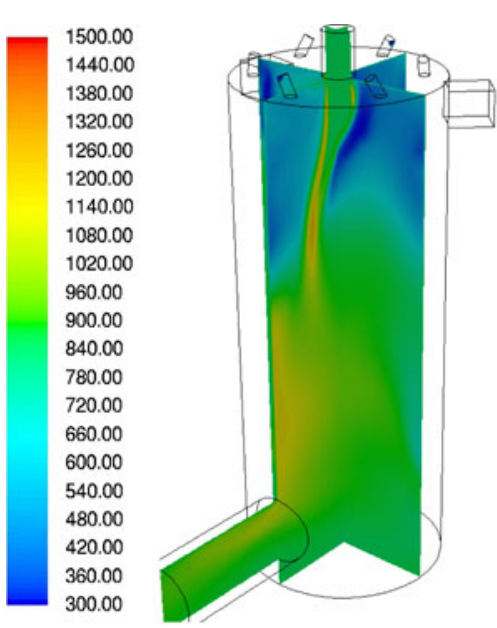

(a) $\mathrm{t}=0 \mathrm{~s}$

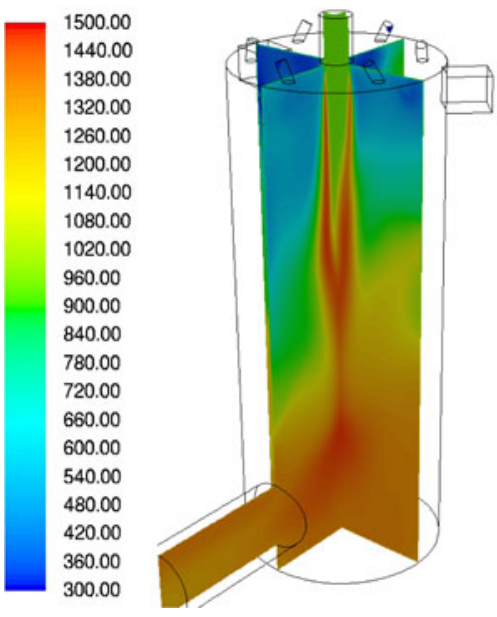

(d) $t=0 \mathrm{~s}$

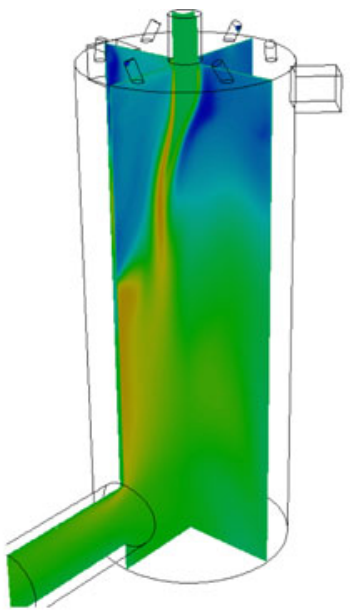

(b) $\mathrm{t}=1 \mathrm{~s}$

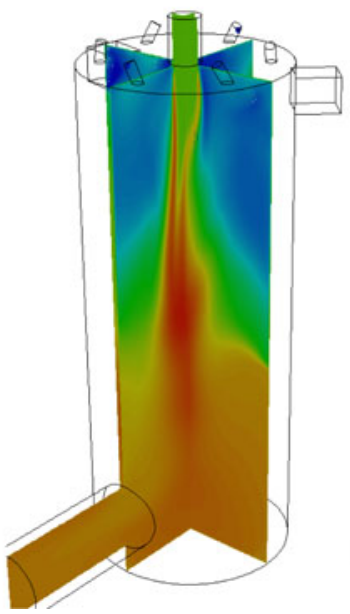

(e) $t=1 s$

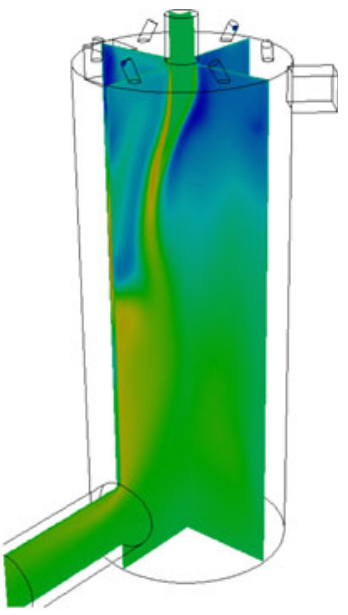

(c) $t=2 s$

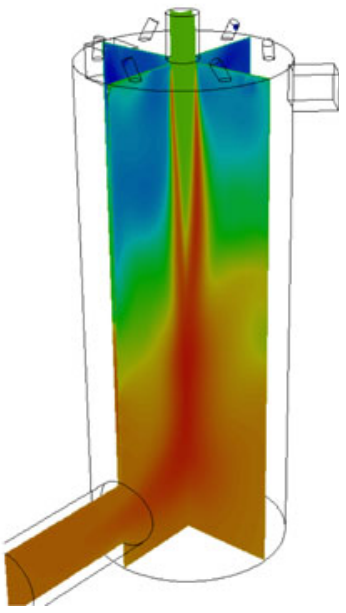

(f) $t=2 s$

Fig. 10 Temperature field in the combustion chamber. The syngas produced from feathers (SG3) is burning with small and large syngas flux (gasifier output): $\mathbf{a}, \mathbf{b}$ and $\mathbf{c}-$ low syngas production-case 1B (scale 300-1,500 K); d, e and f-high syngas production-case 2B (scale 300-1,500 K)

lower part of the chamber is filled with hot gases with relatively uniform temperature distribution.

We further analysed maximum temperature observed in the combustion chamber and temperature averaged over the whole volume of the chamber. The summary of these characteristic temperatures is presented in Table 3.

The uniform temperature distribution is easier to achieve when SG3 is burning (cases $1 \mathrm{~B}$ and 2B, Fig. 9). For these cases the differences between maximum and average temperatures are close to $500 \mathrm{~K}$. When syngas production is low (case $1 \mathrm{~B}$ ) and influence of cold air is higher this difference is bigger $-540 \mathrm{~K}$. For high syngas production rate (case $2 \mathrm{~B}$ ) the maximum temperature goes up to $1,500 \mathrm{~K}$ while 
Table 3 The time-averaged value of maximum temperature, volume-average temperature and temperature close to the outlet

\begin{tabular}{llcl}
\hline & $\begin{array}{l}\text { Maximum } \\
\text { temperature } \\
{[\mathrm{K}]}\end{array}$ & $\begin{array}{l}\text { Average } \\
\text { temperature } \\
{[\mathrm{K}]}\end{array}$ & $\begin{array}{l}\text { Outlet } \\
\text { temperature } \\
{[\mathrm{K}]}\end{array}$ \\
\hline Case 1A & 1,750 & 970 & 1,060 \\
Case 2A & 1,880 & 1,220 & 1,610 \\
Case 1B & 1,360 & 820 & 950 \\
Case 2B & 1,510 & 1,020 & 1,270 \\
\hline
\end{tabular}

average temperature increases to more than $1,000 \mathrm{~K}$. The difference then drops to $490 \mathrm{~K}$.

Combustion of SG1 generally leads to higher temperature peaks: $1,750 \mathrm{~K}$ for low syngas production rate (case $1 \mathrm{~A}$ ) and almost $1,900 \mathrm{~K}$ for high syngas production rate (case 2A). The temperature differences are up to $800 \mathrm{~K}$ in the case $1 \mathrm{~A}$ and $660 \mathrm{~K}$ in the case 2A. We discuss later in Section 4.3 that higher temperature peak leads to higher nitrogen oxides emission.

In the simulations (Figs. 9 and 10) the temperature of the lower part of the combustion chamber and outlet temperature are close. The latter can be compared with the measured values from the monitoring system in the gasification plant in Olsztyn (point measurement with a thermocouple located in the outlet). The average measured temperature equals $1,200 \mathrm{~K}$ with standard deviation of $50 \mathrm{~K}$. The case $2 \mathrm{~B}$ has the inlet conditions (flow rate and inlet temperature) close to the operating conditions in Olsztyn. This simulation well reproduces the measured outlet temperature $(1,270 \mathrm{~K})$.

\subsection{Nitrogen oxides formation and emission}

\subsubsection{NO formation mechanisms}

The two main mechanisms of nitrogen oxides generation are Zeldovich (thermal) mechanism active above $1,700 \mathrm{~K}[34,35]$ :

$$
\begin{aligned}
& \mathrm{O}+\mathrm{N}_{2} \leftrightarrow \mathrm{NO}+\mathrm{N} \\
& \mathrm{N}+\mathrm{O}_{2} \leftrightarrow \mathrm{NO}+\mathrm{O} \\
& \mathrm{N}+\mathrm{OH} \leftrightarrow \mathrm{NO}+\mathrm{H},
\end{aligned}
$$

and Fenimore (prompt) mechanism, more important for lower temperatures even around $1,000 \mathrm{~K}[36]$ :

$$
\begin{aligned}
& \mathrm{CH}+\mathrm{N}_{2} \leftrightarrow \mathrm{HCN}+\mathrm{N} \\
& \mathrm{N}+\mathrm{O}_{2} \leftrightarrow \mathrm{NO}+\mathrm{O} \\
& \mathrm{HCN}+\mathrm{OH} \leftrightarrow \mathrm{CN}+\mathrm{H}_{2} \mathrm{O} \\
& \mathrm{CN}+\mathrm{O}_{2} \leftrightarrow \mathrm{NO}+\mathrm{CO} \\
& \mathrm{NH}+\mathrm{H} \leftrightarrow \mathrm{N}+\mathrm{H}_{2} \\
& \mathrm{~N}+\mathrm{OH} \leftrightarrow \mathrm{NO}+\mathrm{H} .
\end{aligned}
$$


In Table 4 we show that increasing initial temperature of fuel leads to higher maximum temperature. For preheated sample SG1 temperature peaks are higher than $1,800 \mathrm{~K}$ and the path of thermal NO production becomes active. Maximum temperatures for burning of sample SG3, even preheated, do not exceed $1,700 \mathrm{~K}$ and the NO production is limited. In Fig. 11a we show that, independently from the initial temperature of fuel, the peaks of the NO profile in the mixture fraction space are an order of magnitude higher for samples SG1-SG2 than for SG3-SG4.

However for gases derived from the same biomass small differences in temperature peaks are visible (see Fig. 3). The maximum temperature of SG2 is slightly higher than SG1 which leads to discrepancies in the NO profiles presented in Fig. 11a. Despite these discrepancies the generation of NO is manifestly larger in wood syngas combustion than with syngas from feathers when thermal NO formation is limited. This conclusion is confirmed by the results of computations with two other combustion mechanisms discussed in Appendix.

Table 4 shows that, for all fuels, ammonia and hydrogen cyanide are present. It is reported [34] that $\mathrm{HCN}$ may be involved in the formation of around $90 \%$ of nitric oxide via prompt mechanism. In Fig. 12 one may notice that the HCN peaks an order of magnitude higher than the peaks of ammonia mass fraction, which supports the claim that $\mathrm{HCN}$ plays the dominant role.

The third possible mechanism of $\mathrm{NO}$ formation, which involves $\mathrm{HCN}$ and $\mathrm{NH}_{3}$, is fuel-NO mechanism. When coal is burning it is assumed that nitrogen bound in the fuel forms hydrogen cyanide and ammonia [34]. However, when fuel produced from biomass gasification is considered, possible path of conversion of fuel-bound nitrogen is more complex. Especially for fixed-bed updraft gasification this process is not yet fully understood [37]. The first problem is that during biomass gasification and biomass combustion more ammonia is formed than hydrogen cyanide $[37,38]$. The second point is the presence of tar. Recent experiments [39] showed that up to $90 \%$ of fuel-bound nitrogen remains unreleased to producer gas and becomes bound to tar. During tar cracking this bound nitrogen is released as $\mathrm{HCN}, \mathrm{NO}, \mathrm{NH}_{3}$ and $\mathrm{N}_{2}$ but no exact results are available. Since fixed-bed updraft biomass gasification conversion of fuel-bound nitrogen is not yet understood we do not include this path in the present analysis. The fuel-NO will be discussed in Section 4.3.2.

Table 4 Maximum temperature and maximum mass fractions of nitrogen oxides, ammonia and hydrogen cyanide

\begin{tabular}{lllllllc}
\hline & $\begin{array}{l}\text { Initial } \\
\text { fuel temp. } \\
{[\mathrm{K}]}\end{array}$ & $\begin{array}{l}\text { Maximum } \\
\text { temp. } \\
{[\mathrm{K}]}\end{array}$ & $\begin{array}{l}\mathrm{NO} \\
{[\mathrm{mg} / \mathrm{kg}]}\end{array}$ & $\begin{array}{l}\mathrm{NO}_{2} \\
{[\mathrm{mg} / \mathrm{kg}]}\end{array}$ & $\begin{array}{l}\mathrm{N}_{2} \mathrm{O} \\
{[\mathrm{mg} / \mathrm{kg}]}\end{array}$ & $\begin{array}{l}\mathrm{NH}_{3} \\
{[\mathrm{mg} / \mathrm{kg}]}\end{array}$ & $\begin{array}{l}\mathrm{HCN} \\
{[\mathrm{mg} / \mathrm{kg}]}\end{array}$ \\
\hline Syngas & 300 & 1,700 & 32 & 3.8 & 0.8 & 0.2 & 2.6 \\
SG1 & 800 & 1,880 & 69 & 5.3 & 1.0 & 0.8 & 5.8 \\
$\quad$ (wood chips) & 1,000 & 1,960 & 100 & 6.4 & 1.0 & 1.3 & 8.4 \\
& 1,200 & 2,040 & 160 & 8.2 & 1.0 & 2.5 & 14.2 \\
Syngas & 300 & No reactions & & & & & \\
SG3 & 800 & 1,460 & 6 & 1.5 & 0.4 & 0.1 & 0.4 \\
$\quad$ (feathers) & 1,000 & 1,570 & 13 & 2.3 & 0.6 & 0.1 & 1.0 \\
& 1,200 & 1,680 & 23 & 2.8 & 0.7 & 0.3 & 2.0 \\
\hline
\end{tabular}



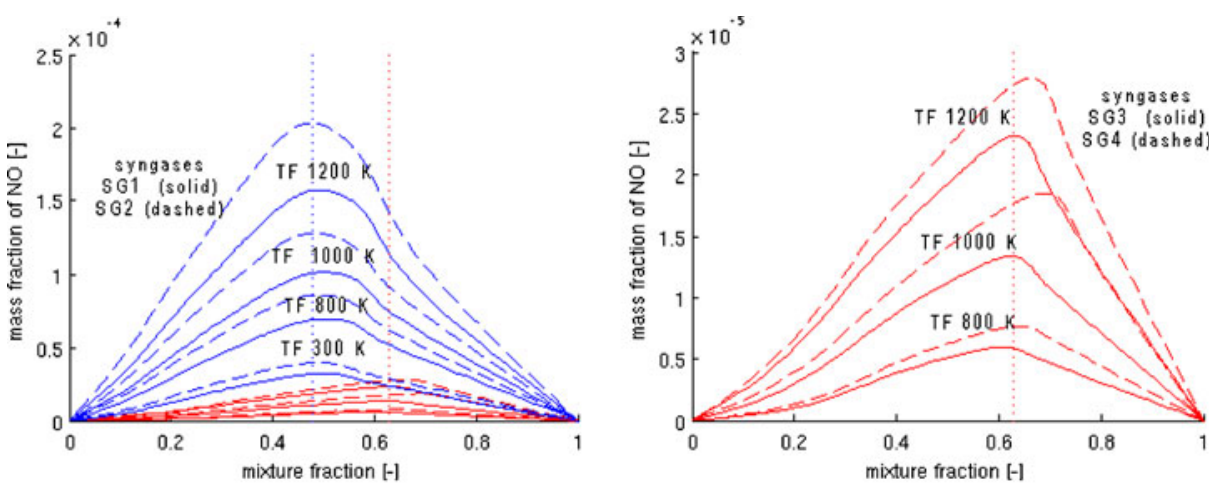

(a) profiles of NO (right figure is rescaled for SG3 and SG4)
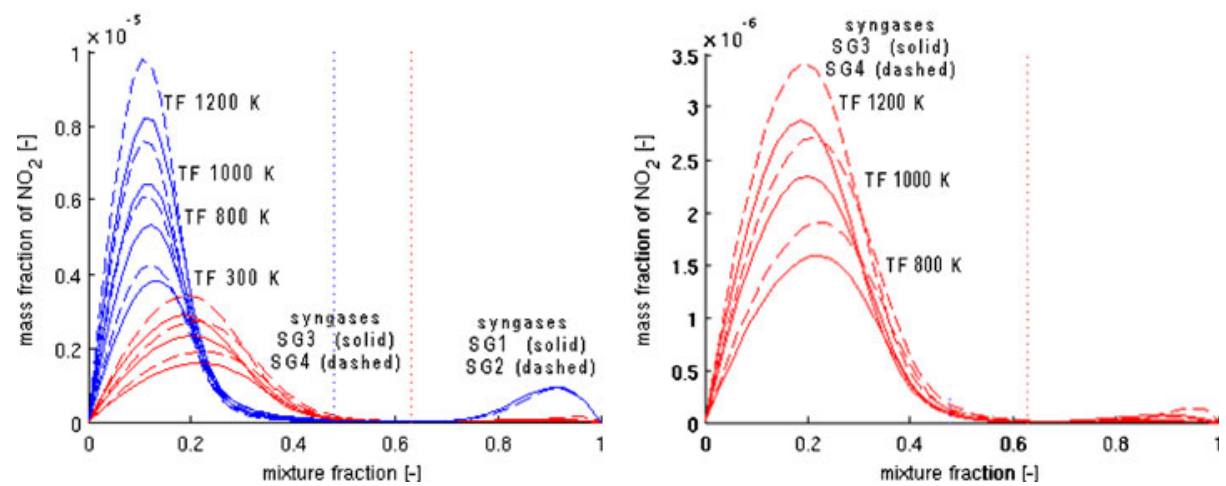

(b) profiles of $\mathrm{NO}_{2}$ (right figure is rescaled for SG3 and SG4)

Fig. 11 Profiles of the mass fraction of $\mathrm{NO}$ and $\mathrm{NO}_{2}$ in the mixture fraction space

The last possible mechanism of NO formation is via the $\mathrm{N}_{2} \mathrm{O}$. This is active for lean mixtures and low temperatures (typically below 1,500 K) [36].

$$
\begin{aligned}
& \mathrm{N}_{2}+\mathrm{O}+\mathrm{M} \leftrightarrow \mathrm{N}_{2} \mathrm{O}+\mathrm{M} \\
& \mathrm{N}_{2} \mathrm{O}+\mathrm{O} \leftrightarrow \mathrm{N}_{2}+\mathrm{O}_{2} \\
& \mathrm{~N}_{2} \mathrm{O}+\mathrm{O} \leftrightarrow \mathrm{NO}+\mathrm{NO} \\
& \mathrm{N}_{2} \mathrm{O}+\mathrm{H} \leftrightarrow \mathrm{N}_{2}+\mathrm{OH}
\end{aligned}
$$

As this path includes three-body reactions it is typically promoted by high pressure. In atmospheric pressure this mechanism is active but not effective. Table 4 shows that maximum $\mathrm{N}_{2} \mathrm{O}$ mass fractions are small and almost independent of temperature.

Generation of $\mathrm{NO}_{2}$ is active only at low temperature. When preheated fuel is burning temperatures are sufficiently low for $\mathrm{NO}_{2}$ production only in regions with small values of the mixture fractions. For samples SG1-SG2, as can be seen in Fig. 11b, the peaks of $\mathrm{NO}_{2}$ mass fraction extend to mixture fraction 0.2 while for SG3-SG4, due to lower temperature, up to mixture fraction 0.4 . 

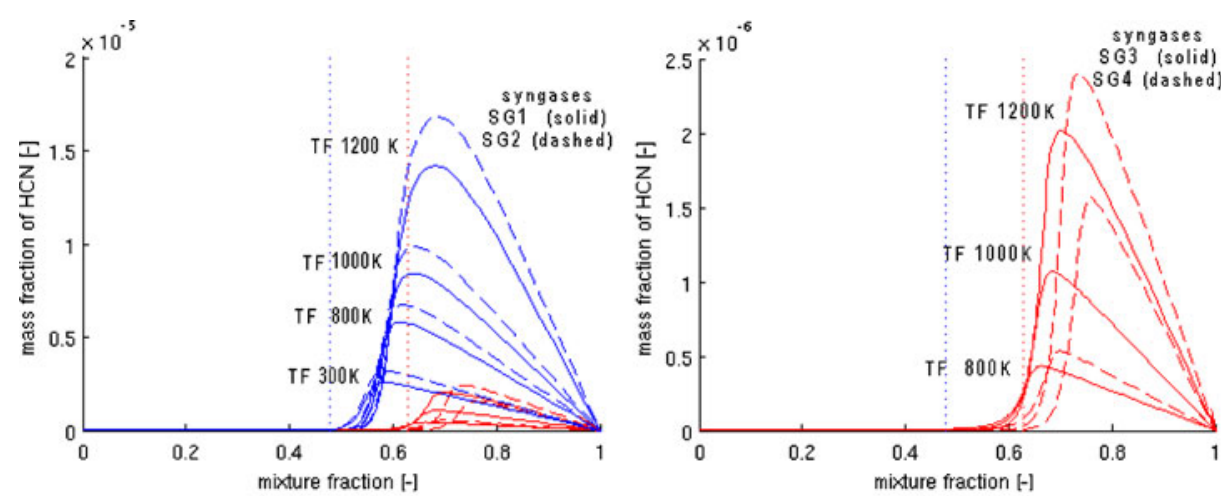

(a) profiles of $\mathrm{HCN}$ (right figure is rescaled for SG3 and SG4)
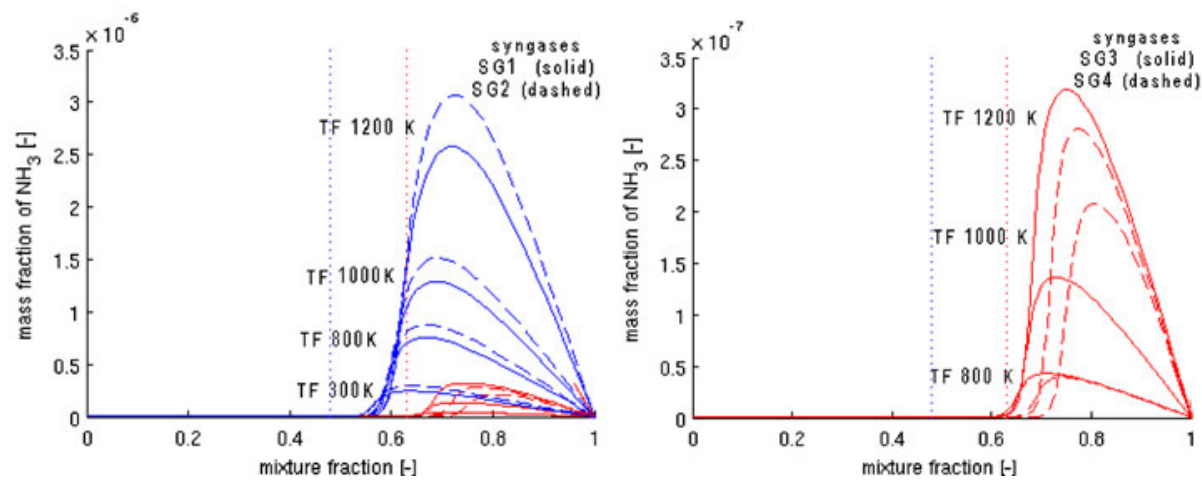

(b) profiles of $\mathrm{HN}_{3}$ (right figure is rescaled for SG3 and SG4)

Fig. 12 Profiles of the mass fraction of $\mathrm{NH}_{3}$ and $\mathrm{HCN}$ in the mixture fraction space

$\mathrm{NO}_{x}$ formation is determined in the post-processing stage of the CFD calculation with ANSYS Fluent 13. The analysis includes the thermal, the prompt and the $\mathrm{N}_{2} \mathrm{O}$ intermediate mechanisms. The $\mathrm{N}$ radical concentration is determined under quasisteady assumption. The concentration of $\mathrm{O}$ and $\mathrm{OH}$ radicals is calculated from partial equilibrium.

\subsubsection{NO emission}

As the environmental regulations on the combustion products become more and more stringent, prediction and mitigation of the pollutant emissions become the key issue. The restrictions on the combustion of gases derived from waste gasification are even more severe. In this case the legal limit of the $\mathrm{NO}_{x}$ emission is $200 \mathrm{mg} / \mathrm{Nm}^{3}$, while the emission of $\mathrm{CO}$ must not exceed $50 \mathrm{mg} / \mathrm{Nm}^{3}$ (guaranteed complete combustion of fuel). These limits have to be calculated with the assumption that oxygen content in exhaust gases is $11 \%$.

The emission of nitric oxide, nitrogen dioxide and carbon monoxide has to be constantly monitored during the day-to-day operation of a waste biomass syngas burner. When the products of combustion do not meet stringent emission norms, 
the level of nitrogen oxides must be lowered by injecting ammonia while reducing carbon monoxide requires auxiliary burners. Both are costly and should be avoided.

Our combustion chamber, developed and successfully implemented in the poultry processing plant, ensures sufficiently low primary emissions making feather gasification commercially viable as well as environmentally friendly. In Fig. 13 we present the emissions of $\mathrm{NO}, \mathrm{NO}_{2}$ and $\mathrm{CO}$ recorded by environmental monitoring system, recalculated for $11 \%$ of oxygen content in the exhaust gases. The emission of carbon monoxide, as presented in Fig. 13d, does not exceed environmental norms. The average emission of $\mathrm{NO}_{x}$ (values in Figs. 13b, c) are well below the limits, however short-time excesses do occur. These short-time peaks are well correlated with the fluctuations of temperature at the outlet of the combustion chamber, plotted in Fig. 13a. If the emission levels exceed the norms, the ammonia injection system for $\mathrm{NO}_{x}$ reduction is switched on. In the normal daily operation of the

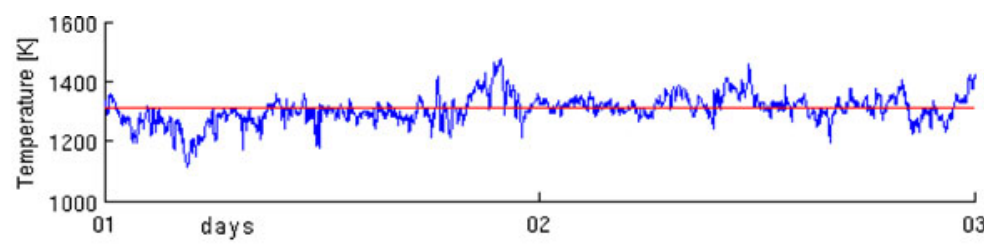

(a) temperature at the outlet,

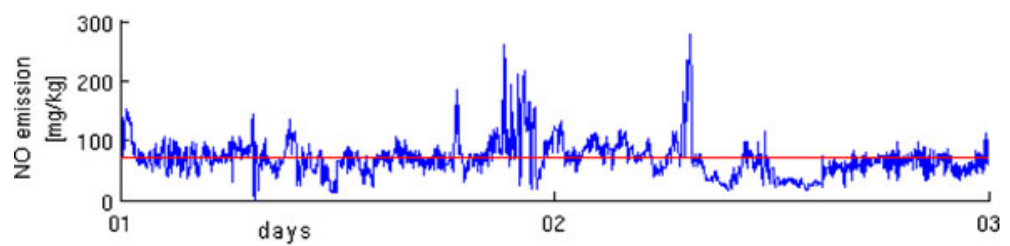

(b) NO emission,

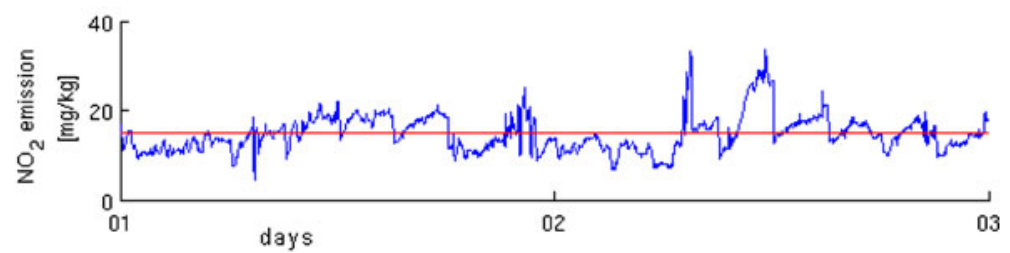

(c) $\mathrm{NO}_{2}$ emission,

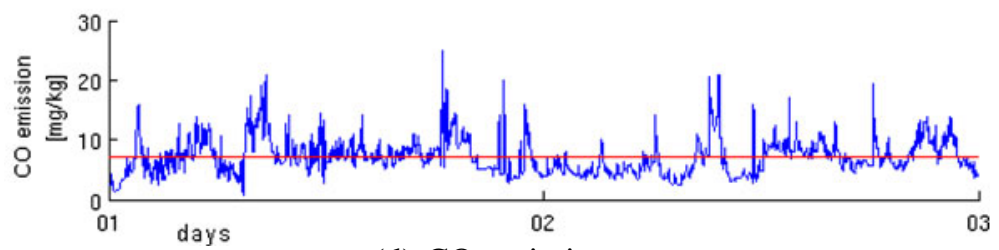

(d) $\mathrm{CO}$ emission.

Fig. 13 The temperature and emissions measured at the outlet of the combustion chamber. The average emission of $\mathrm{CO}$ is $7 \pm 3 \mathrm{mg} / \mathrm{kg}$. The average emission of $\mathrm{NO}$ is $70 \pm 30 \mathrm{mg} / \mathrm{kg}$ and the average emission of $\mathrm{NO}_{2}$ is $15 \pm 4 \mathrm{mg} / \mathrm{kg}$ 
installation ammonia injection is not used. Selected 2-days data shown in Fig. 13 are representative for the operation of this gasification plant, more data can be found in $[4,5,19,20]$.

The results of numerical simulations are summarised in Table 5, where we present the emissions of $\mathrm{NO}, \mathrm{CO}$ and $\mathrm{O}_{2}$, as well as the characteristic temperatures discussed in Section 4.2: maximum temperature, averaged temperature and temperature at the outlet of the combustion chamber. Oxygen content in the flue gases is generally around $10 \%$ by mass, smaller when the rate of syngas production is high (cases $2 \mathrm{~A}$ and $2 \mathrm{~B}$ ). The computed emission of carbon monoxide is very low, which proves that combustion is complete in all considered cases.

When the thermal path of NO formation is activated the emission is correlated with maximum temperature reached in the combustion chamber. When SG1 is burning (cases $1 \mathrm{~A}$ and $2 \mathrm{~A}$ ) temperature peaks are higher than 1,700 $\mathrm{K}$ and thermal path of the NO formation is active. In the case $1 \mathrm{~A}$ maximum temperature is 1,700 $1,800 \mathrm{~K}$ and the $\mathrm{NO}$ emission is around $30 \mathrm{mg} / \mathrm{kg}$, but in the case $2 \mathrm{~A}$ temperature increases to $1,800-1,900 \mathrm{~K}$ and the NO emission exceeds $200 \mathrm{mg} / \mathrm{kg}$. However, in the latter case, oxygen concentration is relatively low (approx. 5-6 \%). With respect to the reference oxygen content of $11 \%$ the emission is approximately $150 \mathrm{mg} / \mathrm{kg}$.

Combustion of SG3 leads to the maximum temperature below 1,600 K, which makes thermal NO formation inactive. Due to low methane content in the fuel, also the prompt path of nitric oxide is limited and consequently the total emission is very low. In the simulation $2 \mathrm{~B}$, which corresponds to the conditions in Olsztyn plant, the predicted $\mathrm{NO}$ emission is below $1 \mathrm{mg} / \mathrm{kg}$. However, the measured average emission of NO (see Fig. 13b) is $70 \pm 30 \mathrm{mg} / \mathrm{kg}$.

Table 5 Characteristic temperatures of the combustion process (maximum temperature, average temperature and outlet temperature) and the emissions of the carbon monoxide, nitric oxide and nitrogen dioxide predicted by the numerical simulations (values at the outlet)

\begin{tabular}{|c|c|c|c|c|c|c|c|}
\hline $\begin{array}{l}\text { Time } \\
\text { [s] }\end{array}$ & $\begin{array}{l}\text { Maximum } \\
\text { temp. } \\
{[\mathrm{K}]}\end{array}$ & $\begin{array}{l}\text { Average } \\
\text { temp. } \\
{[\mathrm{K}]}\end{array}$ & $\begin{array}{l}\text { Outlet } \\
\text { temp. } \\
{[\mathrm{K}]}\end{array}$ & $\begin{array}{l}\mathrm{CO} \\
{[\mathrm{mg} / \mathrm{kg}]}\end{array}$ & $\begin{array}{l}\mathrm{O} \\
{[\mathrm{kg} / \mathrm{kg}]}\end{array}$ & $\begin{array}{l}\mathrm{NO} \\
{[\mathrm{mg} / \mathrm{kg}]}\end{array}$ & $\begin{array}{l}\mathrm{NO}^{\mathrm{a}} \\
{[\mathrm{mg} / \mathrm{kg}]}\end{array}$ \\
\hline \multicolumn{8}{|c|}{ Case 1A: SG1, low production rate } \\
\hline 0 & 1,740 & 972 & 1,090 & 14 & 0.11 & 29 & 29 \\
\hline 1 & 1,770 & 970 & 1,060 & 5.1 & 0.12 & 31 & 34 \\
\hline 2 & 1,750 & 950 & 1,040 & 12 & 0.11 & 26 & 26 \\
\hline \multicolumn{8}{|c|}{ Case $2 \mathrm{~A}$ : SG1, high production rate } \\
\hline 0 & 1,870 & 1,230 & 1,560 & 4.5 & 0.07 & 210 & 160 \\
\hline 1 & 1,880 & 1,210 & 1,600 & 1.8 & 0.06 & 235 & 165 \\
\hline 2 & 1,880 & 1,220 & 1,610 & 3.5 & 0.05 & 240 & 160 \\
\hline \multicolumn{8}{|c|}{ Case 1B: SG3, low production rate } \\
\hline 0 & 1,380 & 860 & 960 & $<0.1$ & 0.13 & $<0.1$ & $<0.1$ \\
\hline 1 & 1,360 & 820 & 920 & $<0.1$ & 0.14 & $<0.1$ & $<0.1$ \\
\hline 2 & 1,350 & 810 & 910 & $<0.1$ & 0.14 & $<0.1$ & $<0.1$ \\
\hline \multicolumn{8}{|c|}{ Case 2B: SG3, high production rate } \\
\hline 0 & 1,510 & 1,010 & 1,270 & $<0.1$ & 0.08 & $<0.1$ & $<0.1$ \\
\hline 1 & 1,520 & 1,020 & 1,260 & $<0.1$ & 0.07 & $<0.1$ & $<0.1$ \\
\hline 2 & 1,500 & 1,020 & 1,290 & $<0.1$ & 0.08 & $<0.1$ & $<0.1$ \\
\hline
\end{tabular}

${ }^{\mathrm{a}}$ Emission calculated for $11 \%$ of $\mathrm{O}_{2}$ in flue gases. 
This large discrepancy leads to the conclusion that for the feathers-derived syngas the most important source of NO must be fuel-bound nitrogen, which is not included in the numerical model. As we discussed in Section 4.3.2 fuel-NO mechanism is not fully understood for combustion of gases obtained in updraft, fixed-bed gasification of biomass. Although the fuel-NO appears to be the major source of NO emitted in Olsztyn, it is not efficient. Even the material with such high nitrogen content as feathers (up to $20 \%$ of nitrogen in dry mass) yields as little as $100 \mathrm{mg} / \mathrm{kg}$ of NO in the flue gas.

\section{Conclusions}

The low-calorific syngas from waste biomass, including the gas derived from the gasification of feathers, can be a valuable fuel for direct combustion on industrial scale. However, standard burners for low-calorific fuel cannot be used due to high NO emission. Custom-designed combustion chamber for burning syngas derived from waste biomass has been investigated in this paper.

The results of numerical simulations, which are in agreement with direct observations and measurements taken in the gasification plants, show that combustion is stable but not steady. Typically oscillatory modes occur and the jet of fuel is precessing on the characteristic time scale of seconds. These results of the numerical simulations have been later confirmed independently by video recordings with a high-speed camera.

The results of the simulations and measurements consistently show that in all cases stable combustion can be achieved in which emission of nitrogen oxides stays below the legal limit and the emission of carbon monoxide is marginal (combustion is complete).

The simulations revealed the relative importance of different NO formation paths. When maximum temperature is lower than $1,600 \mathrm{~K}$, the thermal, prompt and $\mathrm{N}_{2} \mathrm{O}$ intermmediate paths of NO formation are marginal. The fuel-bound nitrogen is therefore the main mechanism of nitric oxide generation.

Acknowledgements Part of this work was supported by the strategic program of scientific research and experimental development of the Polish National Centre for Research and Development: "Advanced Technologies for Energy Generation"; Task 4. "Elaboration of Integrated Technologies for the Production of Fuels and Energy from Biomass as well as from Agricultural and other Waste Materials".

Kamil Kwiatkowski acknowledges financial support from the Foundation for Polish Science Programme VENTURES (operated within the Innovative Economy Operational Programme 20072013).

Numerical computations were performed in the Interdisciplinary Centre for Computational and Mathematical Modelling (ICM), University of Warsaw, grant number G34-8.

Open Access This article is distributed under the terms of the Creative Commons Attribution License which permits any use, distribution, and reproduction in any medium, provided the original author(s) and the source are credited.

\section{Appendix: Combustion Mechanisms}

The flamelet structure was computed using the GRI3 mechanism [27]. Since the analysed fuels have not been previously investigated we compute the solutions of the 


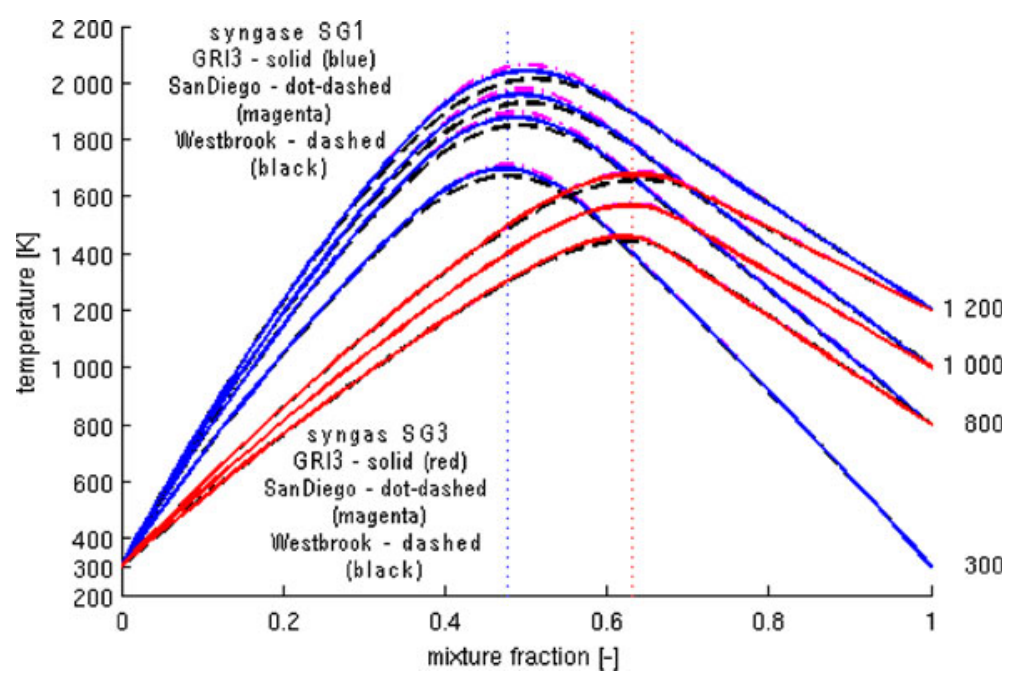

Fig. 14 Comparison of temperature profiles in the mixture fraction space for three combustion mechanisms: GRI3 [27] (solid lines), 'San Diego' [28] (dot-dashed lines) and 'Westbrook' [29] (dashed lines)

Table 6 The comparison of the GRI3 [27], 'San Diego' [28] and 'Westbrook' [29] kinetic mechanisms: the maximum temperatures of combustion and the peaks of pollutants distribution in mixture fraction space computed for SG1 and SG3 for the scalar dissipation rate $5 \mathrm{~s}^{-1}$

\begin{tabular}{lcllllll}
\hline $\begin{array}{l}\text { Combustion } \\
\text { mechanism }\end{array}$ & $\begin{array}{l}\text { Initial } \\
\text { fuel temp. } \\
{[\mathrm{K}]}\end{array}$ & $\begin{array}{l}\text { Maximum } \\
\text { temp. } \\
{[\mathrm{K}]}\end{array}$ & $\begin{array}{l}\mathrm{NO} \\
{[\mathrm{mg} / \mathrm{kg}]}\end{array}$ & $\begin{array}{l}\mathrm{NO}_{2} \\
{[\mathrm{mg} / \mathrm{kg}]}\end{array}$ & $\begin{array}{l}\mathrm{N}_{2} \mathrm{O} \\
{[\mathrm{mg} / \mathrm{kg}]}\end{array}$ & $\begin{array}{l}\mathrm{NH}_{3} \\
{[\mathrm{mg} / \mathrm{kg}]}\end{array}$ & $\begin{array}{l}\mathrm{HCN} \\
{[\mathrm{mg} / \mathrm{kg}]}\end{array}$ \\
\hline Syngas SG1 (wood chips) & & & & & & & \\
GRI3 & 300 & 1,700 & 32 & 3.8 & 0.8 & 0.2 & 2.6 \\
SanDiego & 300 & 1,710 & 11 & 0.7 & 0.3 & 0.1 & 0.7 \\
Westbrook & 300 & 1,670 & 42 & 4.3 & 0.8 & 0.5 & 1.6 \\
GRI3 & 800 & 1,880 & 70 & 5.3 & 1.0 & 0.8 & 5.8 \\
SanDiego & 800 & 1,900 & 37 & 1.5 & 0.3 & 0.4 & 1.8 \\
Westbrook & 800 & 1,850 & 93 & 7.8 & 1.0 & 1.1 & 3.2 \\
GRI3 & 1,000 & 1,960 & 100 & 6.4 & 1.0 & 1.3 & 8.4 \\
SanDiego & 1,000 & 1,980 & 66 & 2.1 & 0.3 & 0.7 & 3.0 \\
Westbrook & 1,000 & 1,930 & 125 & 8.4 & 1.0 & 1.5 & 4.5 \\
GRI3 & 1,200 & 2,040 & 160 & 8.2 & 1.0 & 2.6 & 14.2 \\
SanDiego & 1,200 & 2,060 & 125 & 3.2 & 0.3 & 1.8 & 5.4 \\
Westbrook & 1,200 & 2,010 & 200 & 11.5 & 1.1 & 2.6 & 9.0 \\
Syngas SG3 (feathers) & & & & & & \\
GRI3 & 800 & 1,460 & 6.0 & 1.6 & 0.5 & 0.0 & 0.4 \\
SanDiego & 800 & 1,460 & 1.5 & 0.2 & 0.2 & 0.0 & 0.1 \\
Westbrook & 800 & 1,445 & 6.4 & 1.2 & 0.5 & 0.0 & 0.2 \\
GRI3 & 1,000 & 1,570 & 13 & 2.3 & 0.6 & 0.1 & 1.0 \\
SanDiego & 1,000 & 1,570 & 4 & 0.4 & 0.2 & 0.0 & 0.3 \\
Westbrook & 1,000 & 1,560 & 12 & 1.9 & 0.6 & 0.1 & 0.7 \\
GRI3 & 1,200 & 1,680 & 23 & 2.9 & 0.8 & 0.3 & 2.0 \\
SanDiego & 1,200 & 1,685 & 8.5 & 0.5 & 0.2 & 0.1 & 0.6 \\
Westbrook & 1,200 & 1,660 & 17 & 2.1 & 0.8 & 0.3 & 1.4 \\
\hline
\end{tabular}


Eqs. 1 and 2 with other combustion mechanisms. First is the San Diego kinetics [28], second is 'Westbrook' [29]. The comparison of the temperature profile, presented in Fig. 14, shows that small discrepancies are seen only in the peaks. The differences in the maximum temperature are in the range of $50 \mathrm{~K}$ for SG1 and only in the range of $20 \mathrm{~K}$ for SG3. In Table 6 peaks of the profiles of nitrogen-containing species are summarised for both gases and for all analysed levels of fuel preheating. The discrepancies between the mechanisms are substantial, reaching $50 \%$, but the trends are always the same. The generation of NO is manifestly larger for wood syngas combustion than in burning syngas from feathers.

\section{References}

1. Warnecke, R.: Gasification of biomass: comparison of fixed bed and fluidized bed gasifier. Biomass Bioenerg. 18(6), 489-497 (2000)

2. Arena, U.: Process and technological aspects of municipal solid waste gasification. A review. Waste Manage. 32(4), 625-639 (2012)

3. Beenackers, A.: Biomass gasification in moving beds, a review of European technologies. Renew. Energ. 16(1-4), 1180-1186 (1999)

4. Dudyński, M., Kwiatkowski, K., Bajer, K.: From feathers to syngas-technologies and devices. Waste Manage. 32(4), 685-691 (2012)

5. Dudyński, M., Kwiatkowski, K., Sosnowska, M.: Solid residues from gasification of biomass. In: 14th International Waste Management and Landfill Symposium (2013)

6. Igawa, S., Yamagishi, T., Matsui, T.: Steam production from spent mushroom bed applying fixed-bed gasification technique. In: Proceedings of 19th European Biomass Conference and Exhibition, pp. 1314-1318 (2011)

7. Lee, S., Choi, K., Lee, J., Kim, J.: Gasification characteristics of combustible wastes in a 5 ton/day fixed bed gasifier. Korean J. Chem. Eng. 23, 576-580 (2006)

8. Pereira, E.G., da Silva, J.N., de Oliveira, J.L., Machado, C.S.: Sustainable energy: A review of gasification technologies. Renew. Sust. Energ. Rev. 16(7), 4753-4762 (2012)

9. Kwiatkowski, K., Bajer, K., Wȩdołowski, K.: Turbulent combustion of biomass syngas. Arch. Mech. 64, 511-527 (2012)

10. Wei, Z., Li, X., Xu, L., Tan, C.: Optimization of operating parameters for low NOx emission in high-temperature air combustion. Energ. Fuel 26, 2821-2829 (2012)

11. Andersen, J., Jensen, P.A., Hvid, S.L., Glarborg, P.: Experimental and numerical investigation of gas-phase freeboard combustion. Part 2: fuel NO formation. Energ. Fuel 23(12), 5783-5791 (2009)

12. Andersen, J., Jensen, P.A., Meyer, K.E., Hvid, S.L., Glarborg, P.: Experimental and numerical investigation of gas-phase freeboard combustion. Part 1: main combustion process. Energ. Fuel 23(12), 5773-5782 (2009)

13. Coelho, P.J., Peters, N.: Numerical simulation of a mild combustion burner. Combust. Flame 124(3), 503-518 (2001)

14. Mancini, M., Schwöppe, P., Weber, R., Orsino, S.: On mathematical modelling of flameless combustion. Combust. Flame 150, 54-59 (2007)

15. Shuster, A., Zieba, M., Scheffkecht, G., Wunning, J.: Optimisation of conventional biomass combustion system by applying Flameless Oxidation. In: 15th IFRF Members Conference, Pisa, Italy (2007)

16. Al-Halbouni, A., Rahms, H., Gorner, K.: An efficient combustion concept for low calorific gases. In: International Conference on Renewable Energies and Power Quality ICREPQ'07 (2007)

17. Ilmurzynska, J., Jagiello, K., Re miszewski, K.: Badanie procesu spalania gazu ze zgazowania biomasy w palniku typy flox w instalacji zakładu zamer. Tech. rep., Institute of Power Engineering, Warsaw (2007) (in Polish)

18. Kwiatkowski, K., Górecki, B., Gryglas, W., Korotko, J., Dudyński, M., Bajer, K.: Numerical modeling of biomass pyrolysis-heat and mass transport models. Numer. Heat Transf. Part A 64(3), 216-234 (2013) 
19. Kwiatkowski, K., Krzysztoforski, J., Bajer, K., Dudyński, M.: Gasification of feathers for energy production-a case study. In: Proceedings of 20th European Biomass Conference and Exhibition, Milan 2012, pp. 1858-1862 (2012)

20. Kwiatkowski, K., Krzysztoforski, J., Bajer, K., Dudyński, M.: The efficency of heat production from the gasification of feathers. In: Venice Symposium 2012, Fourth International Symposium on Energy from Biomass and Waste. CISA Publisher, Italy (2012)

21. Marculescu, C., Stan, C.: Poultry processing industry waste to energy conversion. Energ. Procedia 6, 550-557 (2011)

22. Chmielniak, T., Sciazko, M., Zawistowski, J., Dudyński, M.: Pilot-plat scale tests on fixed-bed biomass gasification technology. Chem. Rev. 85(8-9), 1247-1251 (2006) (in Polish)

23. Kwiatkowski, K., van Dyk, J.: Industrial experiment on fixed-bed gasification with biomass in poland. part 1: operation observations and mass balance. Tech. rep., Sasol Technology (2013)

24. Peters, N.: Turbulent Combustion. Cambridge University Press (2000)

25. Peters, N.: Laminar diffusion flamelet models in non-premixed turbulent combustion. Prog. Energ. Combust. Sci. 10(3), 319-339 (1984)

26. ANSYS Fluent 13. Theory Guide, Ansys Inc., Canonsburg, US (2010)

27. Smith, G.P., Golden, D.M., Frenklach, M., Moriarty, N.W., Eiteneer, B., Goldenberg, M., Bowman, C.T., Hanson, R.K., Song, S., Gardiner, W.C., Lissianski, V.V., Qin, Z.: http://www. me.berkeley.edu/gri_mech/. Accessed 7 Mar 2012

28. Chemical-kinetic Mechanisms for Combustion Applications: San diego mechanism web page, Mechanical and Aerospace Engineering (Combustion Research) University of California at San Diego. http://combustion.ucsd.edu. Accessed 7 Mar 2012

29. Hori, M., Matsunaga, N., Marinov, N., Pitz, W., Westbrook, C.: An experimental and kinetic calculation of the promotion effect of hydrocarbons on the $\mathrm{NO}-\mathrm{NO}_{2}$ conversion in a flow reactor. Proc. Combust. Inst. 1, 389-396 (1998)

30. Abtahizadeh, E., van Oijen, J., de Goey, P.: Numerical study of mild combustion with entrainment of burned gas into oxidizer and/or fuel streams. Combust. Flame 159(6), 2155-2165 (2012)

31. de Joannon, M., Sorrentino, G., Cavaliere, A.: MILD combustion in diffusion-controlled regimes of hot diluted fuel. Combust. Flame 159(5), 1832-1839 (2012)

32. Aminian, J., Galletti, C., Shahhosseini, S., Tognotti, L.: Numerical investigation of a MILD combustion burner: analysis of mixing field, chemical kinetics and turbulence-chemistry interaction. Flow Turbulence Combust. 88, 597-623 (2012)

33. Kwiatkowski, K., Jasiński, D., Bajer, K.: Numerical simulations of industrialscale combustion chamber-LES versus RANS. J. Phys. Conf. Ser. 318, 092009 (2011)

34. Hill, S., Smoot, L.D.: Modeling of nitrogen oxides formation and destruction in combustion systems. Prog. Energ. Combust. Sci. 26(4-6), 417-458 (2000)

35. Turns, S.: An Introduction to Combustion: Concepts and Applications. McGraw-Hill Education (2011)

36. Warnatz, J., Maas, U., Dibble, R.: Combustion: Physical and Chemical Fundamentals, Modeling and Simulation, Experiments, Pollutant Formation. Springer (2006)

37. Sethuraman, S., Huynh, C.V., Kong, S.C.: Producer gas composition and NOx emissions from a pilot-scale biomass gasification and combustion system using feedstock with controlled nitrogen content. Energ. Fuel 25(2), 813-822 (2011)

38. Stubenberger, G., Scharler, R., Zahirovic, S., Obernberger, I.: Experimental investigation of nitrogen species release from different solid biomass fuels as a basis for release models.. Fuel 87(6), 793-806 (2008)

39. Mandl, C., Obernberger, I., Scharler, I.: Characterisation of fuel bound nitrogen in the gasification process and the staged combustion of producer gas from the updraft gasification of softwood pellets. Biomass Bioenergy 35(11), 4595-4604 (2011) 